\title{
Toward a more physical representation of precipitation scavenging in global chemistry models: cloud overlap and ice physics and their impact on tropospheric ozone
}

\author{
J. L. Neu ${ }^{1, *}$ and M. J. Prather ${ }^{1}$ \\ ${ }^{1}$ Department of Earth System Science, University of California, Irvine, California, USA \\ * now at: Jet Propulsion Laboratory, Pasadena, California, USA
}

Correspondence to: J. L. Neu (jessica.1.neu@jpl.nasa.gov)

Received: 25 June 2011 - Published in Atmos. Chem. Phys. Discuss.: 31 August 2011

Revised: 3 March 2012 - Accepted: 5 March 2012 - Published: 5 April 2012

\begin{abstract}
Uptake and removal of soluble trace gases and aerosols by precipitation represents a major uncertainty in the processes that control the vertical distribution of atmospheric trace species. Model representations of precipitation scavenging vary greatly in their complexity, and most are divorced from the physics of precipitation formation and transformation. Here, we describe a new large-scale precipitation scavenging algorithm, developed for the UCI chemistrytransport model (UCI-CTM), that represents a step toward a more physical treatment of scavenging through improvements in the formulation of the removal in sub-gridscale cloudy and ambient environments and their overlap within the column as well as ice phase uptake of soluble species. The UCI algorithm doubles the lifetime of $\mathrm{HNO}_{3}$ in the upper troposphere relative to a scheme with commonly used fractional cloud cover assumptions and ice uptake determined by Henry's Law and provides better agreement with $\mathrm{HNO}_{3}$ observations. We find that the process of ice phase scavenging of $\mathrm{HNO}_{3}$ is a critical component of the tropospheric $\mathrm{O}_{3}$ budget, but that $\mathrm{NO}_{\mathrm{x}}$ and $\mathrm{O}_{3}$ mixing ratios are relatively insensitive to large differences in the removal rate. Ozone abundances are much more sensitive to the lifetime of $\mathrm{HNO}_{4}$, highlighting the need for better understanding of its interactions with ice and for additional observational constraints.
\end{abstract}

\section{Introduction}

We describe a new treatment for large-scale precipitation scavenging that was developed with a focus on improving two aspects of the parameterization: (1) the overlap between cloud condensate and precipitation, which determines the partitioning between in-cloud and below-cloud scavenging and (2) the scavenging of soluble gases, in particular $\mathrm{HNO}_{3}$, by frozen precipitation. Together, these processes constitute the largest inter-model differences in the representation of gas phase precipitation scavenging in modern global chemistry-transport models (CTMs).

Recent research has highlighted the importance of accounting for processes that are only partially resolved on the modeled grid scales, specifically, the effects of fractional cloud cover on radiative heating rates (e.g. Collins, 2001), cloud and precipitation microphysics (Jakob and Klein, 1999 and 2000), and photolysis rates (Neu et al., 2007). With scavenging, as with microphysics, the ambiguity of interpreting the overlap of fractional clouds in successive layers is complicated by the fact that the precipitating volume of the grid box is not necessarily the same as the local cloud volume. Furthermore, microphysical processes controlling the uptake of gases and aerosols by precipitation (and hence their rate of scavenging and removal from the atmosphere) differ within clouds where precipitation originates and/or accretes condensed water as it falls, and clear air where evaporation occurs. Most precipitation scavenging schemes differentiate between the cloud fraction and the precipitating fraction in 
some way, but here we define these volumes and their associated microphysical processes consistently based on a vertical overlap model in which cloudy layers connected by precipitation are maximally overlapped. We use this model to assess the importance of vertical cloud structure in scavenging by large-scale precipitation. The development of this cloud treatment provides a paradigm for scavenging in global-scale models that can be tested against cloud-resolving models.

Precipitation scavenging of $\mathrm{HNO}_{3}$ is the primary removal mechanism for reactive nitrogen in the atmosphere. Observations from recent aircraft campaigns have confirmed laboratory studies indicating $\mathrm{HNO}_{3}$ uptake by cloud ice (Zondlo et al., 1997; Abbatt, 1997; Ullerstam et al., 2005; Kondo et al., 2003; Voigt et al., 2006, 2007; Popp et al., 2007; Scheuer et al., 2010); thus frozen precipitation may play an important role in modulating $\mathrm{O}_{3}$ production by lightning or aircraft sources of $\mathrm{NO}_{\mathrm{x}}$ in the upper troposphere. While there are clear differences in the interaction of gas-phase species with ice and liquid water, most models that include scavenging by frozen precipitation do not make any distinction between cold and warm clouds. Exceptions include a version of the CSIRO climate model described by Rotstayn and Lohmann (2002), which explicitly models snow scavenging of sulfur species via impaction and accretion of liquid droplets, and a version of MATCH-MPIC described in von Kuhlman and Lawrence (2006), which represents the equilibrium uptake of $\mathrm{HNO}_{3}$ on ice according to dissociative Langmuir theory (Abbatt, 1997; Tabazedeh et al., 1999). Here, we calculate the partitioning of $\mathrm{HNO}_{3}$ into cloud ice as a function of temperature based on a burial model, in which $\mathrm{HNO}_{3}$ is deposited on ice crystal surfaces along with water vapor and is effectively buried as the crystals grow (Kärcher and Basko, 2004; Ullerstam and Abbatt, 2005; Kärcher and Voigt, 2006). We assume that new precipitation forms from aggregation of these $\mathrm{HNO}_{3}$-containing ice crystals, which are in equilibrium with conditions where they originate, and then calculate additional uptake of ice and $\mathrm{HNO}_{3}$ by riming as the precipitation falls.

\subsection{Scavenging processes}

Most global CTMs treat scavenging by large-scale precipitation as a combination of two processes: (1) in-cloud, or nucleation scavenging (rainout), which is the local uptake of soluble gases and aerosols by the formation of initial cloud droplets and their conversion to precipitation; and (2) belowcloud, or impaction scavenging (washout), which is the collection of soluble species from the interstitial air by falling hydrometeors. In addition to precipitation from large-scale clouds, some models include gravitational settling of cirrus cloud particles and the gases trapped in them (Lawrence and Crutzen, 1998; hereafter LC98). Small-scale, convective precipitation is also effective in scavenging soluble gases, particularly from convective updrafts (e.g. Balkanski et al., 1993; Mari et al., 2000). Typically, this precipitation occurs over a small fraction of the grid box and is tied to the convective cumulus mass fluxes. We do not address scavenging by cloud ice sedimentation or convective precipitation here.

Despite the immense complexity of the microphysics involved in the formation, growth, and evaporation of precipitation, scavenging is usually modeled as a simple, first-order loss process of the species $X(\mathrm{~kg})$ in a model grid box, such that $\mathrm{d} X / \mathrm{d} t=-\lambda_{\mathrm{SCAV}} X$, where $\lambda_{\mathrm{SCAV}}$ is a loss frequency $\left(\mathrm{s}^{-1}\right)$. Over a time step $\Delta t$, the amount of tracer scavenged is $X_{\mathrm{SCAV}}=X_{o} F_{\mathrm{SCAV}}\left(1-\exp \left(-\lambda_{\mathrm{SCAV}} \Delta t\right)\right)$, where $F_{\mathrm{SCAV}}$ is the fraction of the grid box subject to scavenging (e.g. in a cloud or under precipitation) (Rasch et al., 2000). In most CTMs, the loss frequency for in-cloud scavenging depends on the amount of cloud condensate, the partitioning of trace species between gas and condensed water, and the increase in the precipitation rate (i.e. "new" precipitation) in each layer $L\left(\Delta P(L), \mathrm{kg} \mathrm{m}^{-2} \mathrm{~s}^{-1}\right)$. The loss rate for below-cloud scavenging depends on the precipitation rate for hydrometeors falling through the bottom of the layer $(P(L))$ and either the tracer uptake by the liquid/ice phase or a washout coefficient that depends on the mass-transfer rate (for highly soluble gases and small aerosols) or the collision rate (for larger aerosols). Usually $\Delta P$ and $P(L)$ are grid-box-average values rather than rates within the precipitating region. Precipitation rates and cloud water content are taken directly from the underlying meteorological data sets. Since most meteorological models parameterize $\Delta P$ as a combination of autoconversion and accretion processes, in-cloud scavenging implicitly combines the two processes.

The fraction of soluble tracers dissolved in cloud condensate is generally calculated using Henry's Law. Most models use effective Henry's Law coefficients that account for the change in solubility with temperature and the dissociation of species in the aqueous phase. The scavenging sub-model of the ECHAM-MESSy model (Tost et al., 2006) calculates full aqueous phase chemistry in cloud droplets to allow for feedbacks between cloud water $\mathrm{pH}$ and solubility. Comparison between a model that assumes a fixed $\mathrm{pH}$ of rainwater and one using extensive modeling of aqueous phase chemistry finds little difference for species with reversible chemistry in the liquid phase like $\mathrm{HNO}_{3}$ (Tost et al., 2007).

\subsection{Overlap}

The fraction of the grid box in layer $L$ exposed to in-cloud scavenging, $F_{\mathrm{SCAV}}(L)$, varies greatly between models: it may be taken as a constant, set equal to the local cloud fraction, $C F(L)$, or calculated solely from the increase in precipitation rate, $\Delta P(L)$, making assumptions about the relationship between clouds and rain formation. In the latter case, $F_{\mathrm{SCAV}}=\Delta P(L) /(k \cdot(i w c+l w c) \Delta Z)$, where $k$ is the rate of conversion of cloud water to precipitation $\left(\mathrm{s}^{-1}\right)$, $i w c$ and $l w c$ are the condensed ice and liquid water content $\left(\mathrm{kg} \mathrm{m}^{-3}\right)$ in the cloud, and $\Delta Z$ is the layer thickness (Giorgi and Chameides, 1986). For stratiform precipitation, 
$k$ is usually calculated from the precipitation rate and condensed liquid water content, assuming a minimum value of $1 \times 10^{-4} \mathrm{~s}^{-1}$ (Giorgi and Chameides, 1986). Some models use the local value of $F_{\mathrm{SCAV}}$, while others use the largest value of $F_{\mathrm{SCAV}}$ from the overhead cloud layers. For highly soluble species, $F_{\mathrm{SCAV}}$ is a critical parameter since, except at very low rain rates, it limits the amount of tracer that can be removed each time-step (Balkanski et al., 1993). The value of $F_{\mathrm{SCAV}}$ for below-cloud scavenging generally depends on the overhead precipitating fraction, but the process may be limited to cloudy layers with decreasing precipitation or even cloud-free layers with precipitation falling through. Rotstayn and Lohmann (2002) compare the scavenging of sulfur species in the CSIRO climate model, which uses random overlap of cloudy layers with below-cloud scavenging in the clear portion of cloudy layers, to the ECHAM4 model it is based on, which has below-cloud scavenging in cloudfree layers only. They find differences of almost $30 \%$ in the sulfate burden between the two models, most of which can be attributed to the greater efficiency of below-cloud scavenging in the CSIRO model.

Given the sensitivity to the scavenging fraction, we expect removal rates to depend strongly on the overlap between precipitating regions and cloudy regions within a model vertical column. Jakob and Klein (1999 and 2000 - hereafter JK99 and JK00) showed the importance of cloud overlap assumptions for parameterization of cloud microphysics in the ECMWF model. JK99 used maximum-random overlap assumptions to divide each grid box into a large number of different, sub-grid vertical cloud profiles, solved the microphysics in each profile separately (allowing for separation of processes inside clouds, where collision and aggregation occur, and outside clouds, where evaporation occurs), and averaged them to determine grid-mean precipitation and latent heating/moistening rates. They showed large differences in precipitation and evaporation compared to calculating mean values for the whole grid box. JK00 showed that a simpler treatment, in which the precipitation flux in each layer is divided into cloudy and clear sky portions with mean values for precipitation generation and evaporation, respectively, can reproduce most of the features of the more complex JK99 scheme, at much less computational cost.

We implement a cloud-overlap scheme similar to JK00 in the UCI CTM using ECMWF meteorological data and evaluate the impact on the scavenging of highly soluble species. The overlap scheme is described in detail in the Appendix and shown schematically in Fig. A1. We assume maximum overlap of clouds in connected precipitating layers, which closely follows JK00 based on their Fig. 1. The UCI model, like many CTMs, does not have an internal hydrological cycle and the ECMWF fields used here provide only cloud fraction, gridbox-average precipitation rates and cloud/ice water content. Given these inputs, we explicitly calculate the generation, growth, and evaporation of precipitation from the top of the column to the surface. In clouds, we separate the gen-

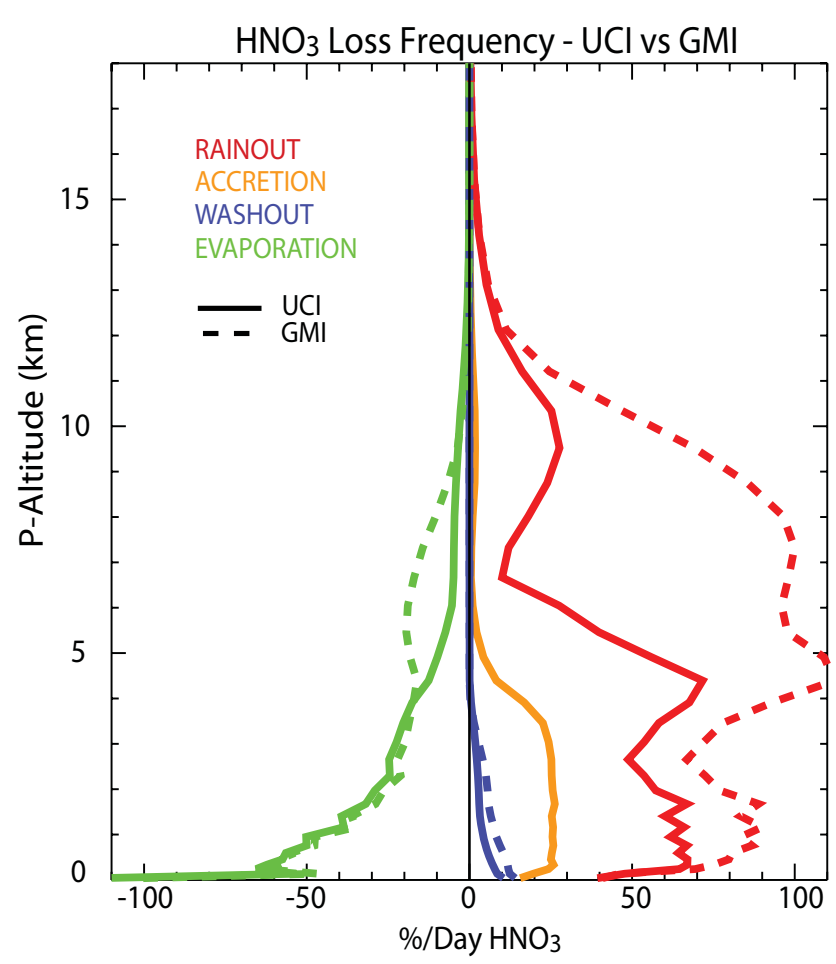

Fig. 1. Profile of globally-averaged $\mathrm{HNO}_{3}$ loss frequency $\left(\%\right.$ day $\left.^{-1}\right)$ for removal by each scavenging process: rainout (red), accretion (orange), washout (blue), and release via evaporation (green). UCI simulation is shown with solid lines, GMI simulation with dashed lines.

eration of new precipitation (autoconversion), which occurs throughout the cloud fraction, from accretion, which occurs only in the portion of the cloud with precipitation overhead. In ambient air, we assume a constant rate of evaporation. Adaptation of the scheme for models that have a more detailed description of the hydrological cycle is discussed in Sect. 6.

For our tests, we use the ECMWF forecast fields (originally $\left.0.5^{\circ}\right)$ averaged to T42 horizontal resolution $\left(\sim 2.8^{\circ}\right)$. There is a great deal of vertical variability in the ECMWF cloud fraction, particularly in the tropics, even at T42, but at this scale there is much sub-grid cloud structure that must be inferred from the mean cloud fractions. We compare our results to those of a standard scavenging formulation based on the Global Modeling Initiative (GMI) CTM (Liu et al., 2007; Duncan et al., 2007) and find large differences in the tropics for highly soluble species such as $\mathrm{H}_{2} \mathrm{O}_{2}, \mathrm{HNO}_{3}$, and $\mathrm{HNO}_{4}$.

\subsection{Uptake by ice and removal by frozen precipitation}

Many gases that are soluble in cloud or rain drops are insoluble in ice because they tend to be expelled as water freezes or to desorb from the ice surface rather than be incorporated into ice crystals that are growing by vapor deposition. Strongly dissociating acids such as $\mathrm{HNO}_{3}$ and $\mathrm{H}_{2} \mathrm{SO}_{4}$ seem to be 
exceptions, likely because they can remain in small, unfrozen pockets in the ice hydrometeor or stick to the ice surface during vapor deposition so that they are buried in successive growth layers (Kärcher and Basko, 2004; Ullerstam and Abbatt, 2005; Kärcher and Voigt, 2006). There is some evidence that $\mathrm{H}_{2} \mathrm{O}_{2}$ may be incorporated in ice (Iribane and Pyshnov, 1990; Conklin et al., 1993; Stuart and Jacobsen, 2003, 2004), but the amount dissolved seems to depend strongly on the details of the freezing process (Mari et al., 2000; Stuart and Jacobson, 2003, 2004; Salzmann et al., 2007). For most ranges of $\mathrm{pH}$ in liquid cloud and rain water, $\mathrm{HNO}_{3}$ is almost entirely in the condensed phase in equilibrium. While Henry's Law can be used to calculate liquid uptake, applying an effective Henry's Law to ice uptake results in excessive precipitation scavenging and unrealistically low $\mathrm{HNO}_{3}$ abundances in the upper troposphere (Lawrence et al., 1999). On the other hand, neglecting rainout by frozen hydrometeors or assuming removal only via washout results in excessively large abundances (Hauglustaine et al., 1998; Mickley et al., 1999; Lawrence et al., 1999; Bey et al., 2001). This has led to the use of arbitrary retention coefficients to reduce the Henry's Law uptake by ice compared to that of liquid water based on the assumption that only some of the gas is retained during freezing (Conklin and Bales, 1993; Crutzen and Lawrence, 2000). The concept of retention, however, implies ice created by freezing of supercooled liquid and is likely not applicable to regions below $\sim 240 \mathrm{~K}$ (above $10 \mathrm{~km}$ ), where ice crystals tend to form via vapor deposition on existing crystals.

Von Kuhlman and Lawrence (2006) represented the equilibrium uptake of $\mathrm{HNO}_{3}$ on cirrus particles according to dissociative Langmuir theory, with uptake limited to a thin surface layer as indicated by laboratory studies from Abbatt (1997) and Tabazedeh et al. (1999). This increased $\mathrm{HNO}_{3}$ abundances in the upper troposphere by about $2 / 3$ compared to using Henry's Law with the coefficient reduced by $99.5 \%$ to account for low retention in ice (von Kuhlmann and Lawrence, 2006). However, several recent studies have shown that surface adsorption models are inadequate for growing ice particles experiencing a wide range of saturations (Kärcher and Basko, 2004; Ullerstam and Abbatt, 2005; Kärcher and Voigt, 2006). Kärcher and Basko (2004) developed a trapping model that accounts for gas-ice interactions in a dynamic, non-steady-state ambient environment. According to this model, trace species deposit on the surface along with water vapor and are buried as ice crystals grow, as long as the rate of desorption is slower than the growth rate of the ice crystals. For rapidly growing crystals, all available gas is buried in the bulk. As the growth rate goes to zero, the surface adsorption limit (i.e. Langmuir theory) is reached. Kärcher and Voigt (2006, hereafter KV06) demonstrate that the burial model successfully reproduces the observed molar ratio of $\mathrm{HNO}_{3}$ to $\mathrm{H}_{2} \mathrm{O}$ on ice crystals as a function of temperature for a large number of aircraft campaigns spanning a wide variety of meteorological conditions. They provide a best estimate of the trapping efficiency based on an em- pirical fit to the data, and show that the efficiency increases with decreasing temperature because of long surface residence times. At warmer temperatures, $\mathrm{HNO}_{3}$ escapes from the surface rapidly and trapping is less efficient despite faster ice growth rates.

We use the KV06 fit to the aircraft measurements, which gives the $\mathrm{HNO}_{3}: \mathrm{H}_{2} \mathrm{O}$ molar ratio in ice as a function of temperature, to determine the partitioning of $\mathrm{HNO}_{3}$ into cloud ice. We assume that "snow" (frozen precipitation, $D>$ $100 \mu \mathrm{m}$ ) initially forms through aggregation of these $\mathrm{HNO}_{3}$ containing ice crystals and irreversibly removes $\mathrm{HNO}_{3}$ from the grid box as it falls. We also model the growth of snow by accretion of solute-containing cloud ice in the layers below. We find that this ice treatment increases $\mathrm{HNO}_{3}$ abundances in the upper troposphere by 100-300\% compared to assuming Henry's Law for ice.

\section{The UCI scavenging treatment}

Our new scavenging algorithm is described in detail in the Appendix. We determine $F_{\mathrm{SCAV}}$ for each removal process (rainout, accretion, and washout), by dividing the precipitating fraction of each level with $P(L)>0$ (i.e. with precipitation falling out the bottom of the layer) into as many as three subgrid fractions: Mixed Cloud (MC), New Cloud (NC), and Ambient (AM), each with a gridbox fraction, precipitation rate, and precipitation diameter. $\mathrm{MC}$ is the portion of the gridbox with precipitation from overhead falling through cloud (and thus it may contain a mixture of precipitation from above and precipitation generated in the layer), $\mathrm{NC}$ is the cloudy portion of the gridbox with no precipitation overhead (which may contain new precipitation generated in the layer), and AM is the portion of the gridbox with precipitation from overhead falling through clear sky. The remainder of the gridbox, CS, is clear sky, with no cloud and no precipitation.

Our rainout represents new precipitation formation only (i.e. autoconversion), which occurs via aggregation of ice crystals to form snow and collision/coalescence of cloud droplets to form rain. Trace gas removal by new precipitation formation depends on the fraction of tracer in the condensed phase and the rate of conversion of cloud ice/water to precipitation. Our below-cloud scavenging by falling precipitation includes both accretion (collection of cloud ice and liquid water), and washout, which includes removal of gases and aerosols from the interstitial air in clouds and ambient air outside of clouds. We model the accretion process explicitly within the subroutine, and trace gas removal by accretion is assumed to be proportional to the amount of condensed water accreted. Washout of highly soluble gases by rain in ambient air is modeled as an impact scavenging process, while scavenging of moderately soluble gases from the ambient air is limited by Henry's Law equilibrium with the falling precipitation. We assume that new precipitation 
Table 1. Ice uptake and cloud overlap assumptions used for the primary set of simulations described in Sect. 3.

\begin{tabular}{|c|c|c|c|c|c|c|c|c|c|c|c|}
\hline & \multicolumn{3}{|c|}{$\mathrm{HNO}_{3}$ Ice Uptake } & \multicolumn{3}{|c|}{$\mathrm{H}_{2} \mathrm{O}_{2}$ Ice Uptake } & \multicolumn{3}{|c|}{$\mathrm{HNO}_{4}$ Ice Uptake } & \multicolumn{2}{|c|}{ Cloud Overlap } \\
\hline & None & KV06 & HLaw & None & LC98 & HLaw & None & KV06 & HLaw & UCI & GMI \\
\hline UCI & & $\checkmark$ & & $\checkmark$ & & & $\checkmark$ & & & $\checkmark$ & \\
\hline UCI-HLAW & & & $\checkmark$ & $\checkmark$ & & & $\checkmark$ & & & $\checkmark$ & \\
\hline UCI-NOICE & $\checkmark$ & & & $\checkmark$ & & & $\checkmark$ & & & $\checkmark$ & \\
\hline GMI & & & $\checkmark$ & $\checkmark$ & & & $\checkmark$ & & & & $\checkmark$ \\
\hline UCI-H2O2 & & $\checkmark$ & & & $\checkmark$ & & $\checkmark$ & & & $\checkmark$ & \\
\hline GMI-H2O2 & & & $\checkmark$ & & & $\checkmark$ & $\checkmark$ & & & & $\checkmark$ \\
\hline UCI-HNO4 & & $\checkmark$ & & $\checkmark$ & & & & $\checkmark$ & & $\checkmark$ & \\
\hline GMI-HNO4 & & & $\checkmark$ & $\checkmark$ & & & & & $\checkmark$ & & $\checkmark$ \\
\hline
\end{tabular}

is formed homogenously throughout the local cloud fraction $(\mathrm{MC}+\mathrm{NC})$, so that $F_{\mathrm{SCAV}}=C F$, while accretion occurs only in the MC fraction of the gridbox. Washout of gases from interstitial and ambient air takes place in the MC and AM fractions. We assume a constant rate of evaporation in $\mathrm{AM}$, which releases gases to the environment along with any large-scale evaporation $(P(L)<P(L-1))$.

For pure ice clouds $(T<240 \mathrm{~K})$ and mixed phase clouds at temperatures $240 \mathrm{~K}<T<258 \mathrm{~K}$, we use KV06 to determine the partitioning into cloud ice. At these temperatures, we assume that the Bergeron-Findeisen mechanism results in the growth of ice crystals by vapor deposition at the expense of cloud water droplets. At temperatures above $240 \mathrm{~K}$, trapping during ice crystal growth is very inefficient because of surface kinetics (Kärcher and Voigt, 2006). Thus, we expect there to be very little uptake of $\mathrm{HNO}_{3}$ between $240 \mathrm{~K}$ and $258 \mathrm{~K}$. For mixed phase clouds with $258 \mathrm{~K}<T<273 \mathrm{~K}$, we use Henry's Law equilibrium with $H_{\text {mix } \mathrm{HNO}_{3}}=0.5 \mathrm{H}_{\mathrm{HNO}_{3}}$ where $H_{\mathrm{HNO}_{3}}$ is the Henry's Law constant for $\mathrm{HNO}_{3}\left(\right.$ moll $\left.{ }^{-1} \mathrm{~atm}^{-1}\right)$. We assume that condensate in this region includes ice and supercooled liquid water, and the value of $0.5 \mathrm{H}_{\mathrm{HNO}_{3}}$ was chosen to represent a mid-point between $\mathrm{H}_{\mathrm{HNO}_{3}}$ and the value for ice used by von Kuhlman, et al. (2003) of $\sim 0.005 \mathrm{H}_{\mathrm{HNO}_{3}}$ based on Conklin et al. (1993). Given the high solubility of $\mathrm{HNO}_{3}$, the uptake is essentially complete. For $T>273 \mathrm{~K}$, we assume that all precipitation is converted to rain. Soluble gases are taken up by the liquid phase according to Henry's Law equilibrium, with highly soluble gases and aerosols fully dissolved in the aqueous phase.

\section{Simulations}

The simulations described here are performed with the UCI CTM run at T42 $\left(\sim 2.8 \times 2.8^{\circ}\right)$ horizontal resolution with 37 vertical levels from the surface to $10 \mathrm{hPa}$. The CTM includes 30 chemical species and a simplified hydrocarbon oxidation scheme for tropospheric chemistry (Wild et al., 2003; Neu et al., 2008), and we use pieced-forecast meteorological fields for the year 2000 from the ECMWF Integrated Forecast System model. The simulations discussed below were run for two repeating years, with the first year discarded as a spin-up period. Results are shown for July unless otherwise noted. In our primary set of simulations (Table 1), we examine the sensitivity of the tropospheric $\mathrm{O}_{3}$ budget to cloud overlap assumptions and the treatment of $\mathrm{HNO}_{3}, \mathrm{H}_{2} \mathrm{O}_{2}$, and $\mathrm{HNO}_{4}$ uptake on ice. We also present parallel simulations that test the sensitivity of the new UCI scavenging formulation to a range of parameters.

Version UCI denotes our new formulation with the cloud overlap scheme described in the Appendix and ice uptake limited to $\mathrm{HNO}_{3}$ only and calculated according the KV06 relationship. To separate the effects of overlap from those of ice scavenging, we also include version UCI-HLAW, in which we use the UCI cloud overlap but ice uptake of $\mathrm{HNO}_{3}$ is calculated as for Henry's Law over liquid water. Version UCI-NOICE includes the cloud overlap for liquid precipitation but has no scavenging by frozen precipitation. Our UCI-HLAW and UCI-NOICE simulations thus span the entire range of likely ice-phase removal rates for $\mathrm{HNO}_{3}$, from a maximum uptake scenario using Henry's Law to a minimum with zero uptake. Version UCI-EVAP5 uses a minimum evaporation rate of $5 \% \mathrm{~km}^{-1}$ as opposed to $25 \% \mathrm{~km}^{-1}$ for the control simulations, thus decreasing the fraction of incloud precipitation and therefore the implied new precipitation formation in each layer. In the year 2000 ECMWF meteorological fields used here, the precipitation was stored as the sum of the convective and large-scale components, which overestimates the large-scale precipitation by as much as a factor of two in the tropics (M. Gauss, personal communication, 2008). Thus we include version UCI-HALFRAIN, in which the precipitation rate is reduced by half as an estimate of the scavenging rate for large-scale precipitation only. Most of the UCI simulations use 1990s emissions inventories, including the EDGAR 2.0 database (Olivier et al., 1996) for $\mathrm{NO}_{\mathrm{x}}, \mathrm{CO}$, and hydrocarbons. Version UCIQUANTIFY adopts the new emissions used by the European 
Union QUANTIFY program (Hoor et al., 2009), which include updated EDGAR emissions and detailed inventories for the road, shipping, and air traffic transport sectors. There is a small net increase $(\sim 14 \%)$ in surface $\mathrm{NO}_{\mathrm{x}}$ emissions, while aircraft $\mathrm{NO}_{\mathrm{x}}$ emissions are scaled to be the same as in the standard UCI simulations. However, the spatial distribution of $\mathrm{NO}_{\mathrm{x}}$ sources is significantly different than in the UCI simulation. The UCI-QUANTIFY simulation thus allows us to examine the importance of the relationship between the spatial patterns of $\mathrm{NO}_{\mathrm{x}}$ sources and the spatial patterns of removal for determining $\mathrm{HNO}_{3}$ abundances in remote regions.

To compare our new scavenging formulation with a "standard" formulation, we adapt the algorithm used by the GMI model (Considine et al., 2005), which is based on Liu et al. (2001). The only difference is that while the GMI model uses the Giorgi and Chameides (1986) expression (Sect. 1.2) for the precipitating fraction of the grid box, here we assume that precipitation is formed throughout the cloud fraction for consistency with the UCI scavenging scheme. The simulations labeled "GMI" here are not run with the full GMI CTM, but with the UCI CTM using the GMI algorithm. Liquid and ice uptake are both determined as a function of temperature using the effective Henry's Law coefficient for liquid water. Species are removed via rainout, as described in Appendix A3.1, when the precipitation rate increases within a layer $\left(P(L)>P(L+1): p_{\mathrm{NEW}}=\Delta P(L)\right)$. Overhead precipitation is assumed to extend the fractional area of the gridbox experiencing rainout, so that $F_{\mathrm{SCAV}}$ is given by the maximum value of $C F$ in the precipitating levels at and above level $L$, and the dissolved fraction of tracer $\left(\chi_{\text {DIS }}\right)$ is determined relative to the tracer mass in $F_{\mathrm{SCAV}}$. Where precipitation remains constant or decreases in layer $L(P(L) \leq P(L+1))$, tracers are removed via washout and there may be release of tracers scavenged from layers above in proportion to the evaporation. As for rainout, $F_{\mathrm{SCAV}}$ for washout is given by the maximum $C F$ of the precipitating levels above. The below cloud scavenging is based on Balkanski et al. (1993) and follows the description in Appendix A3.3 for moderately soluble gases. For highly soluble gases and aerosols, the loss rate is given by $k^{\prime}\left(1 \times 10^{3} \cdot P / \rho_{\mathrm{w}} F_{\mathrm{SCAV}}\right) \Delta t$ where $k^{\prime}$ is a washout loss rate constant of $0.1 \mathrm{~mm}^{-1}$ (Dana and Hales, 1976; Levine and Schwartz, 1982), $\rho_{\mathrm{w}}$ is the density of liquid water, and $1 \times 10^{3}$ is the conversion factor from $\mathrm{m}$ to $\mathrm{mm}$. Version GMI-HALFRAIN, like the UCI version defined above, reduces the precipitation rate by half.

In addition to $\mathrm{HNO}_{3}$, we also examine the sensitivity of $\mathrm{O}_{3}$ to ice scavenging of peroxide $\left(\mathrm{H}_{2} \mathrm{O}_{2}\right)$ and pernitric acid $\left(\mathrm{HNO}_{4}\right) . \mathrm{H}_{2} \mathrm{O}_{2}$ is a source of $\mathrm{OH}$ and $\mathrm{HO}_{2}$, and thus the upper tropospheric $\mathrm{O}_{3}$ budget is sensitive to vertical transport of $\mathrm{H}_{2} \mathrm{O}_{2} \cdot \mathrm{H}_{2} \mathrm{O}_{2}$ is highly soluble in water, but its solubility in ice seems to depend strongly on the details of the freezing process (Stuart and Jacobson, 2003, 2004). Estimates for the retention coefficient in laboratory studies range from nearzero to one (Iribarne and Pyshnov, 1990; Snider et al., 1992; Snider and Huang, 1998; Stuart and Jacobson, 2004). Us- ing a co-condensation uptake mechanism, Mari et al. (2000) found that inefficient scavenging of $\mathrm{H}_{2} \mathrm{O}_{2}$ by ice may explain observations of enhanced $\mathrm{H}_{2} \mathrm{O}_{2}$ in convective outflow. LC98, on the other hand, used a more efficient temperaturedependent ice partitioning based on the laboratory studies of Conklin et al. (1993) and found significant removal of $\mathrm{H}_{2} \mathrm{O}_{2}$ from the upper troposphere via cirrus gravitational settling. Version UCI-H2O2 uses the LC98 $\mathrm{H}_{2} \mathrm{O}_{2}$ ice uptake formulation in addition to the $\mathrm{KV}_{0} 6 \mathrm{HNO}_{3}$ ice uptake to examine the influence of $\mathrm{H}_{2} \mathrm{O}_{2}$ removal on the $\mathrm{HO}_{\mathrm{x}}$ budget of the upper troposphere, with LC98 likely representing a maximum uptake scenario. Version GMI-H2O2 uses Henry's Law uptake over water for both liquid and ice for $\mathrm{HNO}_{3}$ and $\mathrm{H}_{2} \mathrm{O}_{2}$.

Photochemical cycling between $\mathrm{NO}_{\mathrm{x}}$ and $\mathrm{HNO}_{4}$ in the upper troposphere is more rapid than that between $\mathrm{NO}_{\mathrm{x}}$ and $\mathrm{HNO}_{3}$, and hence removal of $\mathrm{HNO}_{4}$ via frozen precipitation scavenging has the potential to significantly affect the upper tropospheric $\mathrm{NO}_{\mathrm{x}}$ budget. There is some evidence from laboratory experiments that $\mathrm{HNO}_{4}$ may adsorb on snow or ice surfaces (Li et al., 1996; Bartels-Rausch et al., 2008), presenting the possibility that it may be scavenged by precipitation in the upper troposphere. Versions UCI-HNO4 and GMI-HNO4, include scavenging of both $\mathrm{HNO}_{3}$ and $\mathrm{HNO}_{4}$ with frozen precipitation. Since $\mathrm{HNO}_{4}$ uptake coefficients have not been established for upper tropospheric conditions, we use the $\mathrm{HNO}_{3}: \mathrm{H}_{2} \mathrm{O}$ molar ratio from KV06 with the appropriate molecular weight for $\mathrm{HNO}_{4}$ to determine the ice uptake in UCI-HNO4. GMI-HNO4 uses Henry's Law uptake for both ice and liquid water. With few $\mathrm{HNO}_{4}$ measurements to constrain our results, these simulations serve only as a sensitivity study of the importance of $\mathrm{HNO}_{4}$ scavenging by ice.

\section{Results}

\section{1 $\mathrm{HNO}_{3}$ scavenging}

\subsection{1 $\mathrm{HNO}_{3}$ scavenging lifetimes}

Global mean profiles of the loss frequency due to large-scale precipitation scavenging for each process (rainout, accretion, washout, and evaporation) in UCI and GMI are shown in Fig. 1. Convective precipitation scavenging occurs in these simulations, but only applies to the updraft fluxes, effectively reducing the source of $\mathrm{HNO}_{3}$ from convection rather than removing ambient $\mathrm{HNO}_{3}$. Rainout is clearly much more efficient than washout at all levels, in agreement with previous studies (e.g. Alheit et al., 1990; Berge, 1993; Liu et al., 2001). The minimum in rainout near $7 \mathrm{~km}$ in UCI is a result of inefficient uptake by ice at warm temperatures. Accretion due to riming of frozen precipitation accounts for very little removal of $\mathrm{HNO}_{3}$, but accretion by liquid precipitation below $4 \mathrm{~km}$ is responsible for $\sim 25 \%$ of the total removal in UCI. GMI only has rainout and washout removal processes, and 
does not partition a portion of the increase in precipitation rate in a layer into accretion. However, the GMI rainout loss frequency is approximately equal to the net loss frequency due to both rainout and accretion in UCI below $4 \mathrm{~km}$. The release of $\mathrm{HNO}_{3}$ by evaporating precipitation is plotted as a negative loss frequency in Fig. 1. The evaporation rate is comparable but opposite in sign to the loss rate by accretion in UCI, but is notably less than the loss rate due to rainout except near the surface in both versions. Evaporation provides an important recycling of scavenged $\mathrm{HNO}_{3}$, extending its residence time in the atmosphere but moving it to lower altitudes.

The mean scavenging lifetime for $\mathrm{HNO}_{3}$ in a given layer (1 to 5 days from Fig. 1) is much shorter than the lifetime for photochemical destruction (about 1 month). Hence its steady-state abundance in the free troposphere is a balance between its sources (primarily conversion of $\mathrm{NO}_{\mathrm{x}}$ emissions to $\mathrm{HNO}_{3}$ ) and large-scale precipitation scavenging. In the tropical upper troposphere (not shown), the lifetime of $\mathrm{HNO}_{3}$ is about 2.5 days in UCI and 1 day in GMI. For comparison, the turnover time in the tropical upper troposphere from the UCI-NOICE simulation is 2 weeks. If $\mathrm{NO}_{\mathrm{x}}$ sources in this region are reasonably well-constrained, then observations of $\mathrm{HNO}_{3}$ should in theory clearly identify the best model for ice uptake.

\subsubsection{Comparison to observed $\mathrm{HNO}_{3}$}

Figure 2 shows a comparison between our model results for UCI, GMI, and UCI-NOICE and the $\mathrm{HNO}_{3}$ measurements from an extensive set of aircraft campaigns covering a variety of locations and seasons (Emmons et al., 2000; http: //www.acd.ucar.edu/gctm/data/; Staudt et al., 2003). Observations have been binned at $5^{\circ} \times 5^{\circ} \times 1 \mathrm{~km}$ resolution and averaged over each campaign region. Asterisks represent mean values while horizontal bars show the central $90 \%$ of the measurements within each bin. Model profiles, plotted as continuous curves, are averaged over the same regions and days of the year (though not the same year since the meteorological fields used here cover only a single year). In the modeled profiles we do not reproduce the meteorology or specific flight-path sampling of each campaign, which would be necessary if we were to use the statistical distributions to rigorously test the full CTM (e.g. Hsu et al., 2004). The comparison presented here is thus more of a test of model climatology.

In all cases, the $\mathrm{HNO}_{3}$ abundance in UCI is larger than in GMI, and UCI generally agrees better with the measurements. The differences in absolute $\mathrm{HNO}_{3}$ abundance between UCI and GMI are small in many cases, but represent large relative changes (100-500\% increases; Sect. 4.1.3) nearly everywhere. The variations in the differences between UCI and GMI $\mathrm{HNO}_{3}$ seen in Fig. 2 reflect spatial inhomogeneities in the differences in the loss frequency. Given the magnitude of the absolute differences in $\mathrm{HNO}_{3}$ abun- dance, uncertainties in emissions (Sect. 4.4), and uncertainties in the measurements, this set of aircraft profiles does not definitively distinguish between the UCI and GMI scavenging representations. However, UCI-NOICE gives much larger $\mathrm{HNO}_{3}$ concentrations than both UCI and GMI in many cases and it is clear that the case of no removal by frozen precipitation is clearly not well-represented by the measurements. This result is in disagreement with von Kuhlman and Lawrence (2006), who found much smaller differences (50-70\%) in $\mathrm{HNO}_{3}$ between simulations with no ice uptake and simulations with either Langmuir or Henry's Law uptake (i.e. the uptake spanned a range similar to our versions UCI-NOICE to GMI). It is impossible to identify the cause of such discrepancies from the published literature alone, but it seems likely that their minimal lightning $\mathrm{NO}_{\mathrm{x}}$ source of $2 \mathrm{Tg} \mathrm{N} \mathrm{yr}^{-1}$ (compared to our $5 \mathrm{Tg} \mathrm{N} \mathrm{yr}^{-1}$ ) would in our model reduce the $\mathrm{HNO}_{3}$ abundances by more than a factor of 2, resulting in a lower sensitivity to ice phase scavenging.

One difficulty of comparing model results to a gridded aircraft climatology is the issue of representativeness, particularly for short-lived species such as $\mathrm{HNO}_{3}$. For example, the UCI simulation tends to systematically underestimate $\mathrm{HNO}_{3}$ from the PEM-Tropics A and B aircraft campaigns, except near Easter Island, while UCI-NOICE tends to provide better agreement with the measurements from the PEM-Tropics campaigns than in other regions. However, the measurements appear to be sensitive to the filtering and averaging applied. Figure $2 \mathrm{w}$ shows an average of all of the South Pacific (Tahiti, Easter Island, Fiji, and a subset of Christmas Island flights) measurements from PEM-Tropics B taken from Staudt et al. (2003). The details of the averaging process were not given, but it is clear that the $\mathrm{HNO}_{3}$ profiles show considerably lower abundances than the simple mean of the values for the individual regions (note difference in scale in the plots). $\mathrm{HNO}_{3}$ from the UCI simulation agrees relatively well with the Staudt et al. (2003) profiles (Fig. $2 \mathrm{w}$ and x), while UCI-NOICE results in too much $\mathrm{HNO}_{3}$. Using the updated QUANTIFY emissions inventory also improves the model-measurement agreement for the PEM-Tropics campaigns (Sect. 4.4).

\subsubsection{Horizontal and vertical structure of $\mathrm{HNO}_{3}$ sensitivity to scavenging}

Differences between UCI and GMI demonstrate the combined influence of KV06 ice scavenging and fractional cloud overlap (Fig. 3a and b), while differences between UCI and UCI-HLAW show the impact of the KV06 ice scavenging only (Fig. 3c). KV06 removes $100-200 \%$ less $\mathrm{HNO}_{3}$ from the upper troposphere than Henry's Law (Fig. 3c), with the largest impact over the northern midlatitude Pacific. Comparing Fig. $3 \mathrm{a}$ and $\mathrm{c}$, it is clear that the largest impact of the UCI fractional overlap treatment is found in the tropics, where there are large vertical variations in cloud fraction. UCI leaves more than $500 \%$ more $\mathrm{HNO}_{3}$ in the tropical 


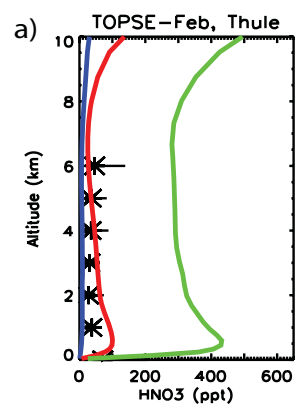

f) TRACE-A, E Brazil Coost

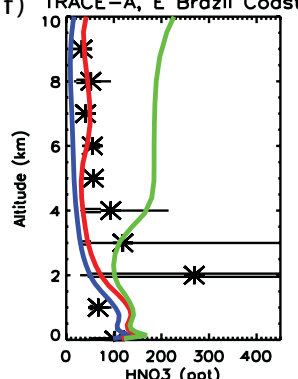

k) PEMWest-A, China Coas

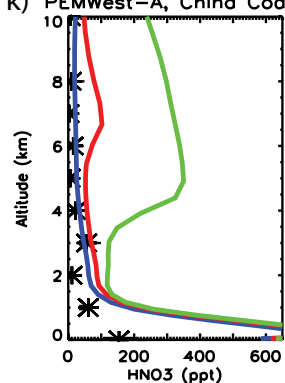

p) PEMTropics-A, Hawaii

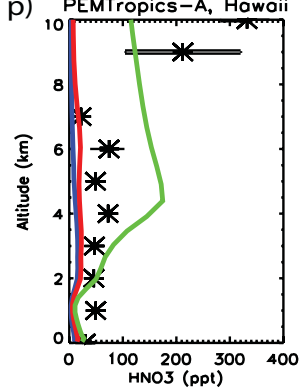

u) PEMTropics-B, Hawaii

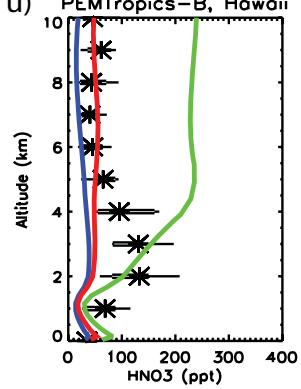

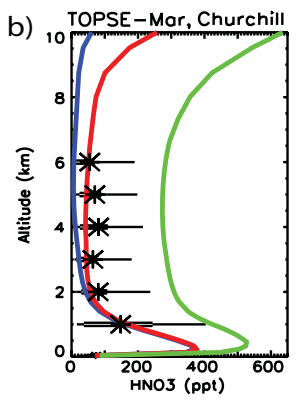

g) TRACE-A, w Africo Coast
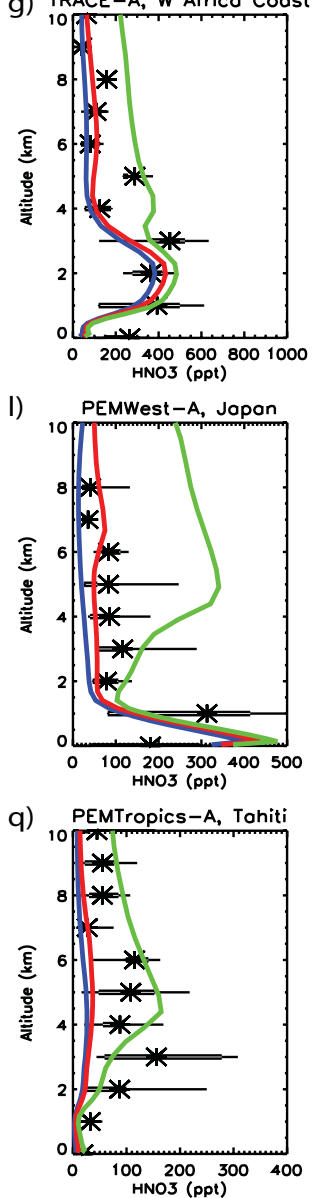

v) PEMTropics-B, Tohiti

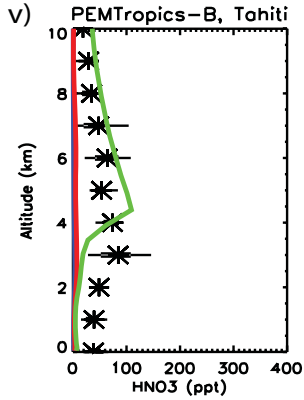

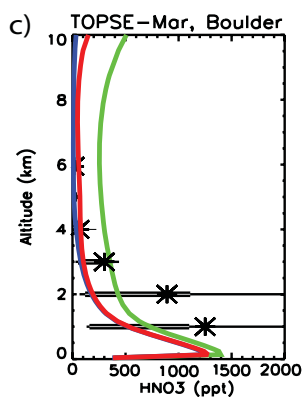

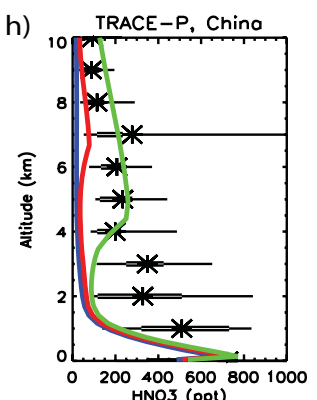

m) PEMWest-B, Chino Coast

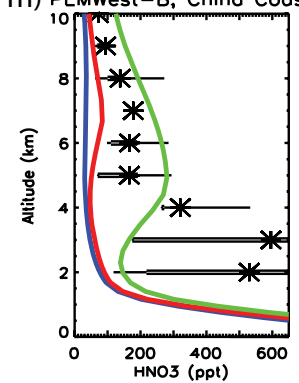

r) PEMTropics-B, Christmas is

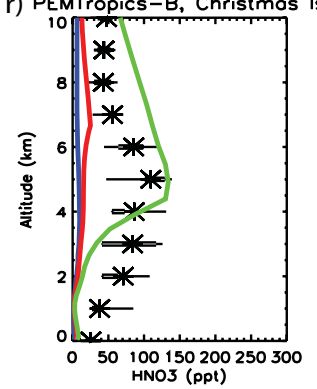

W) PEMTropics-B, S. Pocific

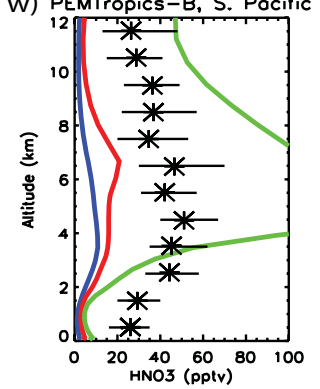

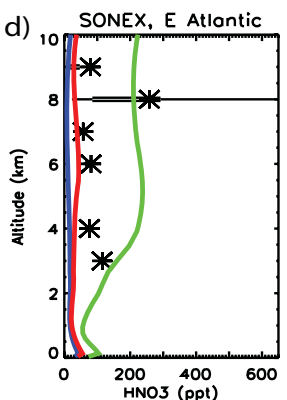
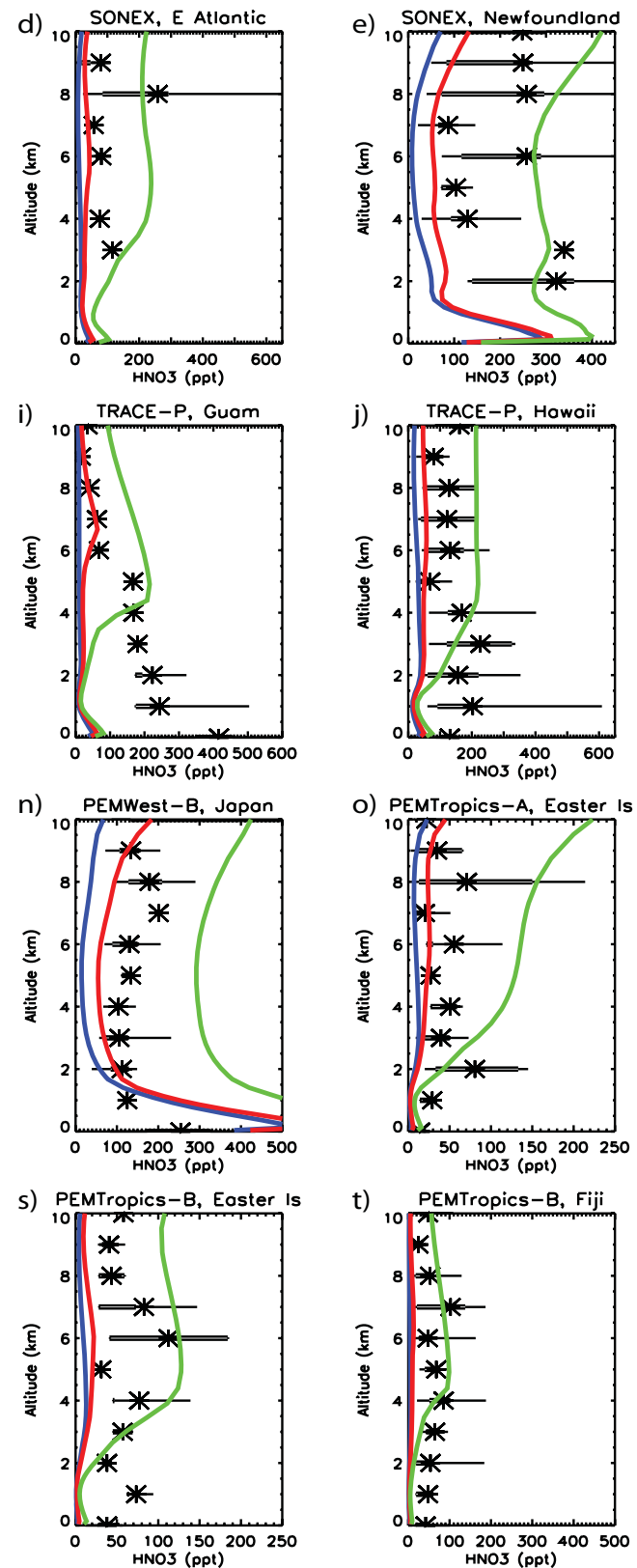

X) PEMTropics-B, N. Pacific

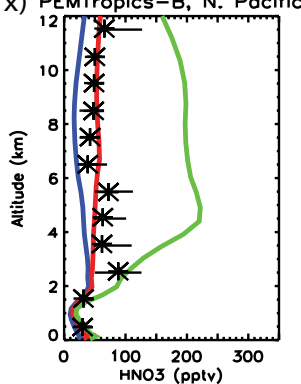

Fig. 2. (a-v) Comparison between UCI (red lines), UCI-NOICE (green lines), and GMI (blue lines) simulations and in situ $\mathrm{HNO}_{3}$ measurements from aircraft campaigns (Emmons et al., 2000; http://www.acd.ucar.edu/gctm/data/). The aircraft measurements are aggregated over each campaign region at $5^{\circ} \times 5^{\circ} \times 1 \mathrm{~km}$ resolution. Asterisks represent mean values, while boxes and whiskers represent the central $50 \%$ and $90 \%$ of the observations, respectively. (w)-(x) Same as (a-v) but data is aggregated over all S. Pacific and N. Pacific PEM-Tropics B flights (Staudt et al., 2003), and horizontal lines indicate minimum and maximum values of $\mathrm{HNO}_{3}$ observed over each region. 

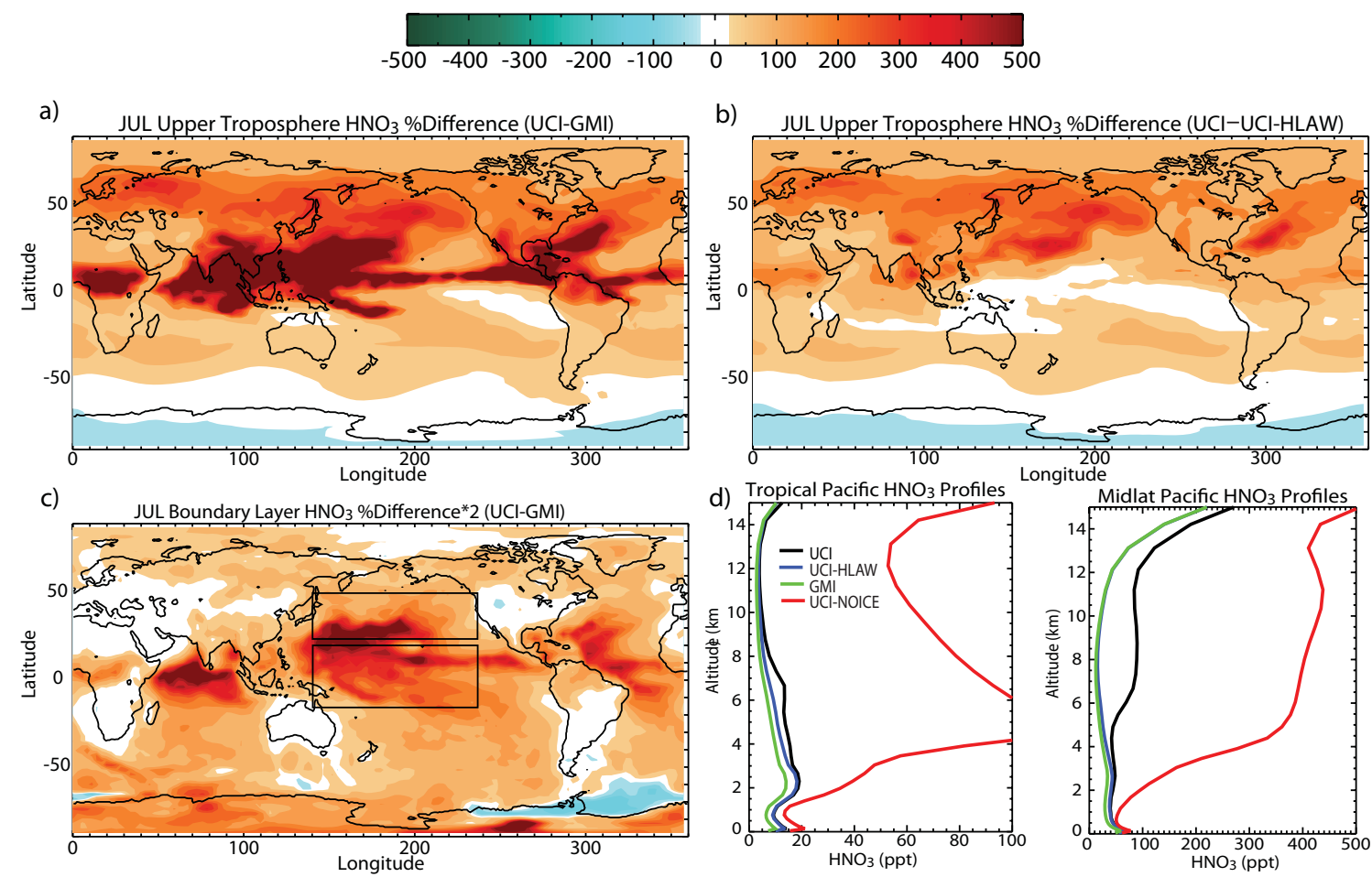

Fig. 3. (a) Latitude-longitude cross section of the percent difference between UCI and GMI (UCI-GMI/UCI) HNO 3 averaged over the upper troposphere $(150 \mathrm{hPa}<p<500 \mathrm{hPa})$ for July. Contour range is -500 to $500 \%$. (b) Same as (a) but for the percent difference between UCI and UCI-HLAW. (c) Same as (a), but $\mathrm{HNO}_{3}$ is averaged over the boundary layer ( $p>850 \mathrm{hPa}$ ) and the percent difference is multiplied by 2 to allow use of the same contour interval. (d) Profiles of $\mathrm{HNO}_{3}$ (ppt) from the UCI (black), UCI-HLAW (blue), GMI (green), and UCI-NOICE (red) simulations, averaged over the Tropical Pacific and Midlatitude Pacific boxes shown in (c).

upper troposphere than GMI. The boundary layer differences between UCI and GMI are almost entirely due to the cloud overlap treatment, as boundary layer differences between UCI and UCI-HLAW are very small (not shown).

Figure 3d shows the model vertical profiles of $\mathrm{HNO}_{3}$ for UCI, UCI-HLAW, UCI-NOICE, and GMI averaged over the regions indicated by the boxes in Fig. 3c. As in Fig. 2, in both regions and indeed throughout most of the atmosphere, UCI-NOICE gives very large $\mathrm{HNO}_{3}$ abundances compared to all three scavenging formulations. The differences between UCI, UCI-HLAW, and GMI are much smaller than the differences between UCI-NOICE and any simulation with ice-phase scavenging. Although the relative difference in $\mathrm{HNO}_{3}$ between UCI and GMI is very large in the tropics (Fig. 3a and b), the absolute difference is quite small because there is so little $\mathrm{HNO}_{3}$ in the tropical upper troposphere in either simulation. In the midlatitudes, on the other hand, the abundances are larger and give rise to larger absolute differences between UCI and GMI. As seen in Fig. 3a and b, the differences between UCI-HLAW and GMI in the tropics are primarily due to the fractional overlap, while the KV06 ice treatment has a much bigger impact in midlatitudes (Fig. 3c).

\subsubsection{Impact of $\mathrm{HNO}_{3}$ scavenging on $\mathrm{NO}_{\mathrm{x}}$ and $\mathrm{O}_{3}$}

The decreased scavenging of $\mathrm{HNO}_{3}$ in UCI compared to GMI results in 10-15\% higher $\mathrm{NO}_{\mathrm{x}}$ concentrations throughout the middle and upper troposphere (Fig. 4) and up to $3 \%$ more upper tropospheric $\mathrm{O}_{3}$, with a pattern that is spatially correlated with the change in $\mathrm{NO}_{\mathrm{x}}$ (not shown). The change in $\mathrm{NO}_{\mathrm{x}}$ is small despite large changes in $\mathrm{HNO}_{3}$ because recycling of $\mathrm{HNO}_{3}$ into $\mathrm{NO}_{\mathrm{x}}$ is a very small source relative to surface pollution, aircraft emissions, and production by lightning, particularly when the $\mathrm{HNO}_{3}$ removal lifetime is less than a few days as it is in both UCI and GMI. Figure 4 also shows that the upper tropospheric differences in $\mathrm{NO}_{\mathrm{x}}$ and $\mathrm{O}_{3}$ are similar for UCI-GMI and UCI-UCI-HLAW, indicating that $\mathrm{NO}_{\mathrm{x}}$ in the upper troposphere is much more sensitive to ice scavenging than to cloud overlap. Ice phase scavenging primarily impacts $\mathrm{HNO}_{3}$ over the midlatitude oceans (Fig. 3b), where other $\mathrm{NO}_{\mathrm{x}}$ sources are small and $\mathrm{HNO}_{3}$ recycling makes a relatively larger contribution, while cloud overlap is important primarily in the tropics (Fig. 3a), where lightning $\mathrm{NO}_{\mathrm{x}}$ production dominates.

In the boundary layer (Fig. 4b), UCI has higher $\mathrm{NO}_{\mathrm{x}}$ abundances than GMI along the flanks of the ITCZ in the Eastern Pacific and over the subtropical Atlantic. These structures 

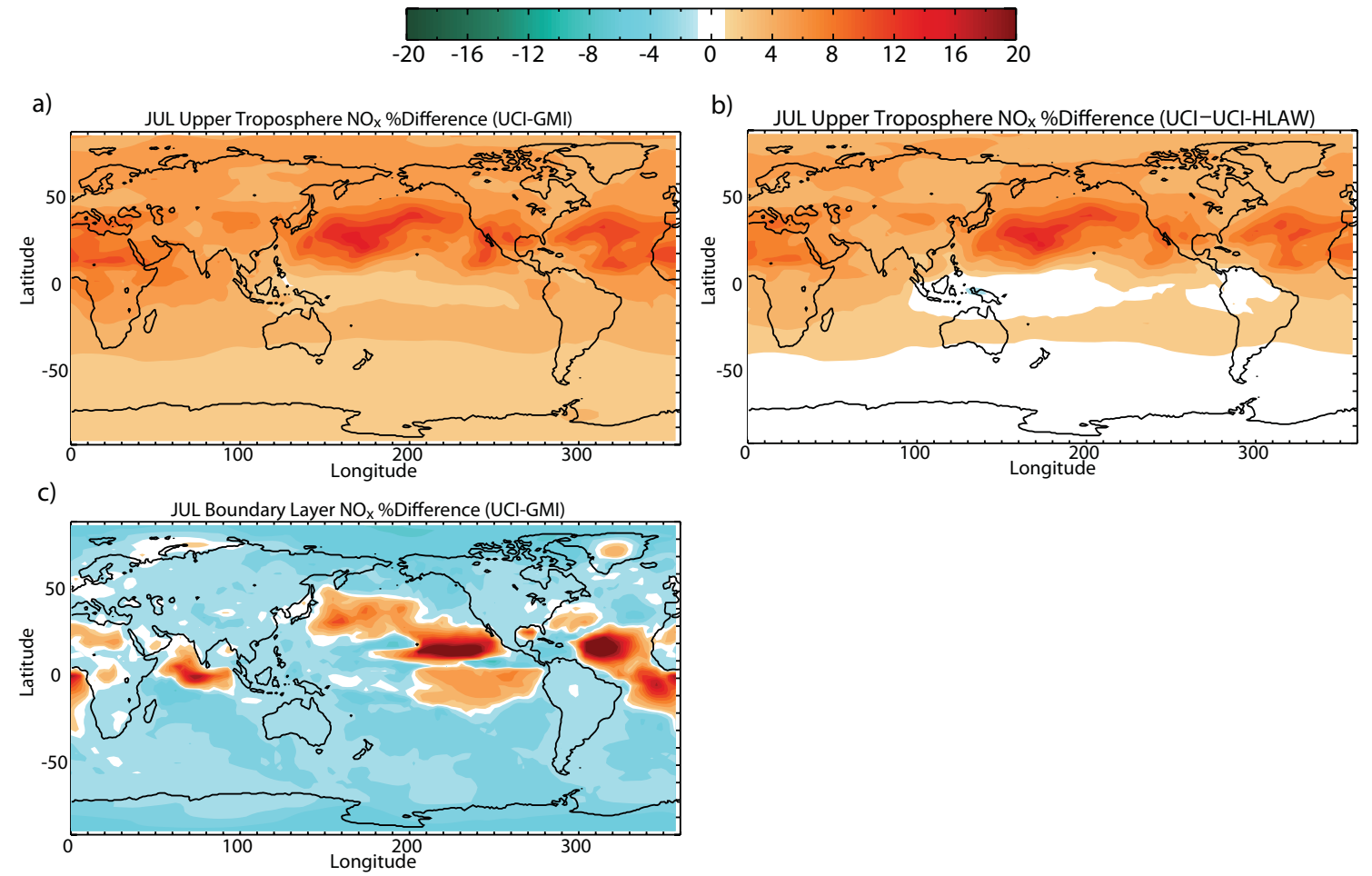

Fig. 4. (a) Latitude-longitude cross section of the percent difference between UCI and GMI (UCI-GMI/UCI) NO $\mathrm{x}_{\mathrm{x}}$ averaged over the upper troposphere $(150 \mathrm{hPa}<p<500 \mathrm{hPa})$ for July. Contour range is -20 to $20 \%$. (b) Same as (a) but for the percent difference between UCI and UCI-HLAW. (c) Same as (a), but $\mathrm{NO}_{\mathrm{x}}$ is averaged over the boundary layer $(p>850 \mathrm{hPa})$.

result from a combination of subsidence of higher- $\mathrm{NO}_{\mathrm{x}}$ air from above and greater evaporation of $\mathrm{HNO}_{3}$ and recycling into $\mathrm{NO}_{\mathrm{x}}$ in the UCI simulation. However, $\mathrm{NO}_{\mathrm{x}}$ abundances are very small $(<20 \mathrm{ppt})$ over most of these regions, so that the absolute change in $\mathrm{NO}_{\mathrm{x}}$ is almost negligible. UCI and UCI-HLAW have almost no difference in boundary layer $\mathrm{NO}_{\mathrm{x}}$ (not shown). Although the absolute changes in boundary layer $\mathrm{NO}_{\mathrm{x}}$ are very small in these simulations, the upper tropospheric $\mathrm{O}_{3}$ response extends throughout the troposphere because of ozone's relatively long lifetime.

Figure 5 shows vertical profiles of $\mathrm{O}_{3}$ averaged over the same boxes as Fig. 3. Differences between UCI and GMI are small, but UCI-NOICE gives much larger $\mathrm{O}_{3}$ abundances than any of the simulations with ice scavenging. Without ice phase removal, the lifetime of $\mathrm{HNO}_{3}$ lifetime in the upper troposphere increases to $\sim 2$ weeks (Sect. 4.1.1), allowing sufficient time for significant recycling into $\mathrm{NO}_{\mathrm{x}} \cdot \mathrm{NO}_{\mathrm{x}}$ increases by $50-100 \%$ in UCI-NOICE relative to the ice scavenging simulations in these regions (not shown), resulting in the $\mathrm{O}_{3}$ increases of 20-30\% seen here. The increase in $\mathrm{NO}_{\mathrm{x}}$ is in fact large enough that supressing ice scavenging perturbs the entire $\mathrm{O}_{3}$ chemical cycle. Reaction of $\mathrm{HO}_{2}$ with $\mathrm{NO}$ shifts $\mathrm{HO}_{\mathrm{x}}$ toward $\mathrm{OH}$, resulting in a net decrease in $\mathrm{HO}_{\mathrm{x}}$, which is reflected in a decrease in $\mathrm{H}_{2} \mathrm{O}_{2}$ (not shown). The global tropospheric $\mathrm{O}_{3}$ column increase between UCI and UCI-NOICE is $2.4 \mathrm{DU}$ (slightly less than $10 \%$ ).
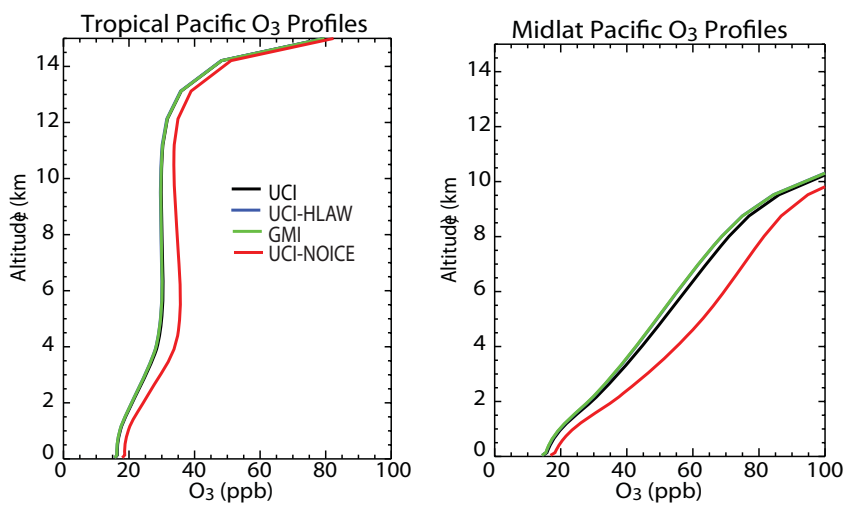

Fig. 5. Profiles of $\mathrm{O}_{3}$ (ppb) from the UCI (black), UCI-HLAW (blue), GMI (green), and UCI-NOICE (red) simulations, averaged over the Tropical Pacific and Midlatitude Pacific boxes shown in Fig. 3c. In both panels, the black, blue, and green lines overlap in part or all of the domain.

\section{$\begin{array}{lll}4.2 & \mathrm{H}_{2} \mathrm{O}_{2} & \text { scavenging }\end{array}$}

The difference in upper tropospheric $\mathrm{H}_{2} \mathrm{O}_{2}$ between UCI$\mathrm{H} 2 \mathrm{O} 2$ and GMI-H2O2 (Fig. 6a), which both include ice phase scavenging of $\mathrm{H}_{2} \mathrm{O}_{2}$ in addition to $\mathrm{HNO}_{3}$, exceeds $200 \%$ ( 40-120 ppt) over large regions and is in many areas 


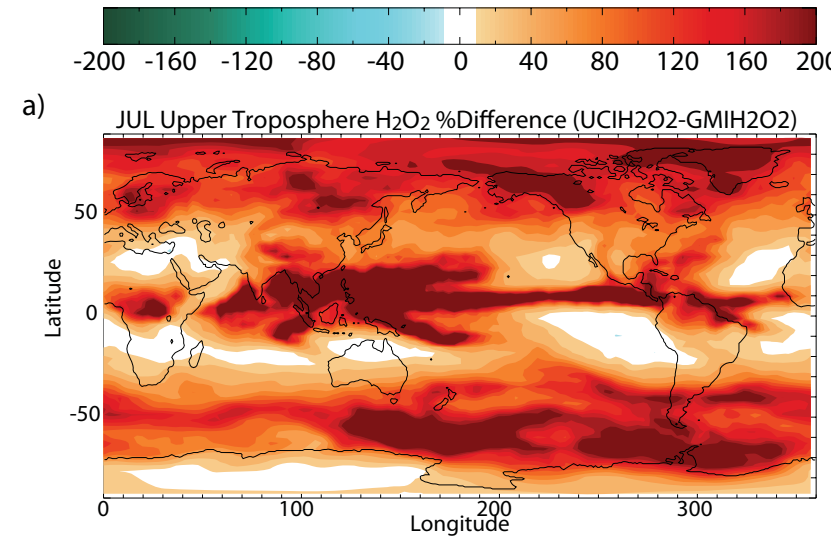

b) JUL Boundary Layer $\mathrm{H}_{2} \mathrm{O}_{2}$ \%Difference *2 (UCIH2O2-GMIH2O2)

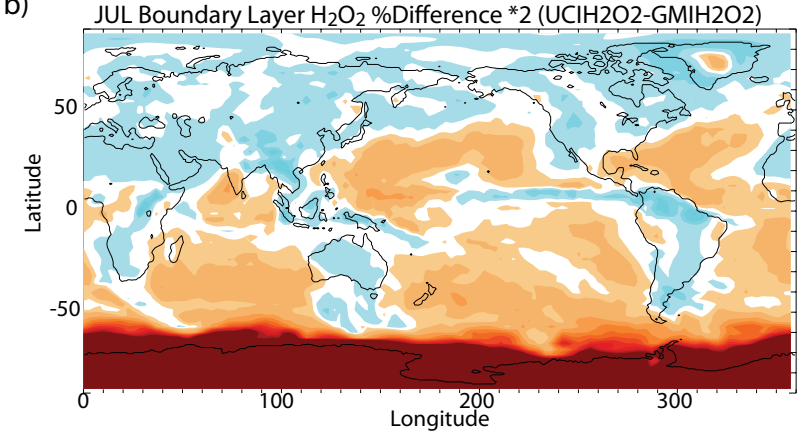

Fig. 6. (a) Latitude-longitude cross section of the percent difference between UCI-H2O2 and GMI-H2O2 $\mathrm{H}_{2} \mathrm{O}_{2}$ averaged over the upper troposphere $(150 \mathrm{hPa}<p<500 \mathrm{hPa}$ ) for July. Contour range is -200 to $200 \%$. (b) Same as (a), but $\mathrm{H}_{2} \mathrm{O}_{2}$ is averaged over the boundary layer $(p>850 \mathrm{hPa})$ and the percent difference is multiplied by 2 to allow use of the same contour interval.

larger than the difference in $\mathrm{HNO}_{3}$ between UCI and GMI (Fig. 3a). The difference in $\mathrm{H}_{2} \mathrm{O}_{2}$ is much smaller than that seen in the upper troposphere throughout most of the middle troposphere and boundary layer (Fig. 6b), except at Southern high latitudes. The difference between LC98 and Henry's Law $\mathrm{H}_{2} \mathrm{O}_{2}$ ice uptake is larger than the difference between KV06 and Henry's Law uptake for $\mathrm{HNO}_{3}$, resulting in a greater sensitivity to the formulation of ice phase scavenging in the upper troposphere. However, the difference in $\mathrm{H}_{2} \mathrm{O}_{2}$ between UCI-NOICE and the $\mathrm{H}_{2} \mathrm{O}_{2}$ ice phase scavenging simulations (not shown) is smaller than the difference seen for $\mathrm{HNO}_{3}$ scavenging. This results from the competing effects of $\mathrm{HNO}_{3}$ ice phase scavenging, which acts to increase $\mathrm{H}_{2} \mathrm{O}_{2}$ in the upper troposphere, as discussed in Sect. 4.1.4, and the decreases due to the ice phase scavenging of $\mathrm{H}_{2} \mathrm{O}_{2}$.

The difference in $\mathrm{O}_{3}$ between the UCI-H2O2 and GMI$\mathrm{H} 2 \mathrm{O} 2$ simulations, in which both $\mathrm{H}_{2} \mathrm{O}_{2}$ and $\mathrm{HNO}_{3}$ are scavenged on ice surfaces, is only slightly smaller than the difference between $\mathrm{UCI}$ and GMI with $\mathrm{HNO}_{3}$ ice scavenging alone (not shown). Likewise, the difference in $\mathrm{O}_{3}$ between UCI-NOICE and UCI-H2O2 is very similar to the difference between UCI-NOICE and UCI, indicating that the impact of
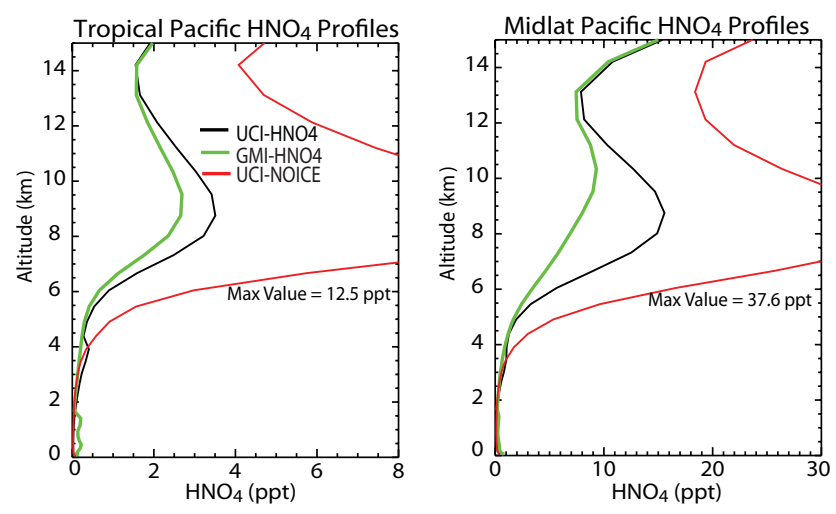

Fig. 7. Profiles of $\mathrm{HNO}_{4}$ (ppt) from the UCI-HNO4 (black), GMIHNO4 (green), and UCI-NOICE (red) simulations, averaged over the Tropical Pacific and Midlatitude Pacific boxes shown in Fig. 3c.

ice phase $\mathrm{H}_{2} \mathrm{O}_{2}$ scavenging on $\mathrm{O}_{3}$ is very small. This is because $\mathrm{H}_{2} \mathrm{O}_{2}$ affects the $\mathrm{O}_{3}$ budget only indirectly through reducing $\mathrm{HO}_{2}$ abundances, and is unimportant except near surface $\mathrm{NO}_{\mathrm{x}}$ sources.

\section{3 $\mathrm{HNO}_{4}$ scavenging}

The relative difference between using KV06 for ice uptake and using Henry's Law is smaller for $\mathrm{HNO}_{4}$ than for $\mathrm{HNO}_{3}$ in the upper troposphere, with maximum $\mathrm{HNO}_{4}$ differences of $\sim 200 \%$ in the tropics. In the boundary layer, the difference is reversed, with GMI-HNO4 having more pernitric acid than UCI-HNO4. As seen in Fig. 7, maximum pernitric acid abundances are found in the middle troposphere, and a great deal of removal takes place in this region. In UCI-HNO4, reevaporation produces a small peak in $\mathrm{HNO}_{4}$ at $\sim 4 \mathrm{~km}$ in the tropics, while in GMI-HNO ${ }_{4}$, the evaporation occurs near the surface, resulting in relatively large abundances in the boundary layer.

There is a greater difference between UCI and GMI upper tropospheric $\mathrm{NO}_{\mathrm{x}}$ when $\mathrm{HNO}_{4}$ is scavenged by ice in addition to $\mathrm{HNO}_{3}$ than for the case of $\mathrm{HNO}_{3}$ ice phase scavenging alone (not shown), and the difference in $\mathrm{O}_{3}$ is also correspondingly larger (Fig. 8, maximum differences of $8 \%$ $(\sim 3 \mathrm{ppb})$ as opposed to $3 \%$ for $\mathrm{HNO}_{3}$ only). In the boundary layer, GMI-HNO4 has more $\mathrm{NO}_{\mathrm{x}}$ than UCI-HNO4 due to the evaporation of precipitating $\mathrm{HNO}_{4}$ discussed above and subsequent cycling back into $\mathrm{NO}_{\mathrm{x}}$. This results in a very different, more locally-driven pattern in the change in boundarylayer $\mathrm{O}_{3}$ than in the $\mathrm{HNO}_{3}$-only runs, where the $\mathrm{O}_{3}$ changes in the boundary layer simply reflect the spatial pattern of the upper tropospheric changes.

\subsection{Sensitivity to rain rate, evaporation, and emissions}

Figure 9 shows the sensitivity of the $\mathrm{HNO}_{3}$ abundance to changes in the rain rate (UCI-HALFRAIN and GMI-HALFRAIN), the assumed rate of precipitation 

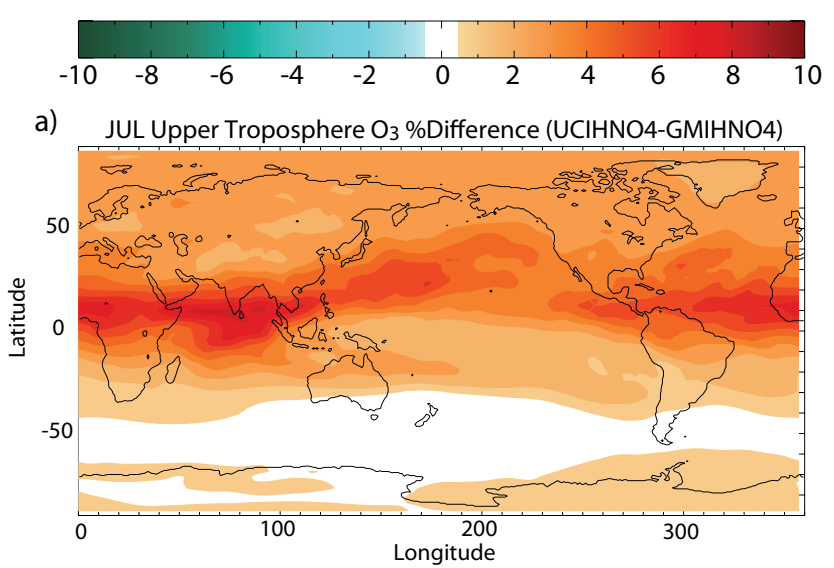

b) JUL Boundary Layer $\mathrm{O}_{3} \%$ Difference (UCIHNO4-GMIHNO4)

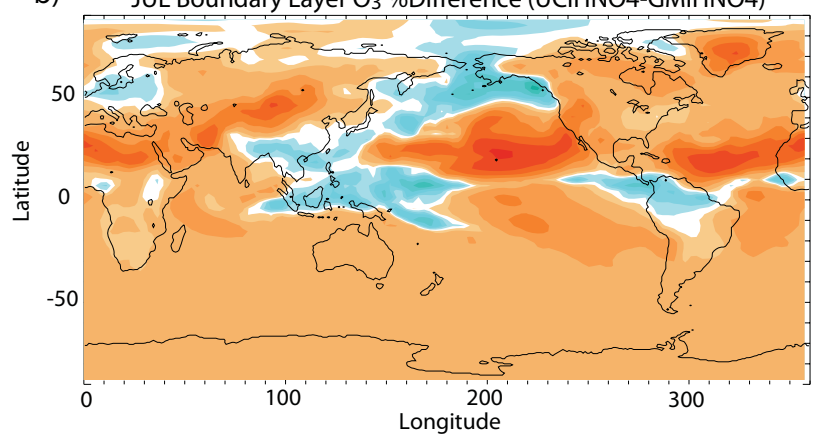

Fig. 8. (a) Latitude-longitude cross section of the percent difference between UCI-HNO4 and GMI-HNO4 $\mathrm{O}_{3}$ averaged over the upper troposphere $(150 \mathrm{hPa}<p<500 \mathrm{hPa})$ for July. Contour range is -10 to $10 \%$. (b) Same as (a), but $\mathrm{O}_{3}$ is averaged over the boundary layer $(p>850 \mathrm{hPa})$.

evaporation in ambient air (UCI-EVAP5), and emissions (UCI-QUANTIFY) for four of the aircraft comparison profiles from Fig. 2. Decreasing the rain rate by $50 \%$ everywhere has very little impact in the GMI scheme, but increases the $\mathrm{HNO}_{3}$ abundance in UCI by $\sim 10-50 \%$. Thus, for smaller precipitation rates that would be more typical of large-scale rain than the combined convective and largescale rates used here, we expect larger absolute differences between the UCI scheme and GMI-type scavenging.

The specification of the evaporation rate in ambient air is a major uncertainty in our parameterization, and the choice of $25 \% \mathrm{~km}^{-1}$ is somewhat arbitrary. However, the $\mathrm{HNO}_{3}$ abundance is relatively insensitive to even a 5 -fold decrease in the evaporation rate. The only profile with a significant sensitivity is the Christmas Island profile, where there is $\sim 25 \%$ more $\mathrm{HNO}_{3}$ in the upper troposphere when the evaporation rate is decreased. While this result is somewhat counterintuitive, given that one might expect less evaporation to result in greater net removal, decreasing the assumed evaporation rate leads to greater partitioning of the grid-box averaged rain rate into the ambient air portion of the gridbox, where removal only takes place via washout, and less partitioning of the rain rate into the cloudy fraction of the gridbox, where removal is much more efficient.
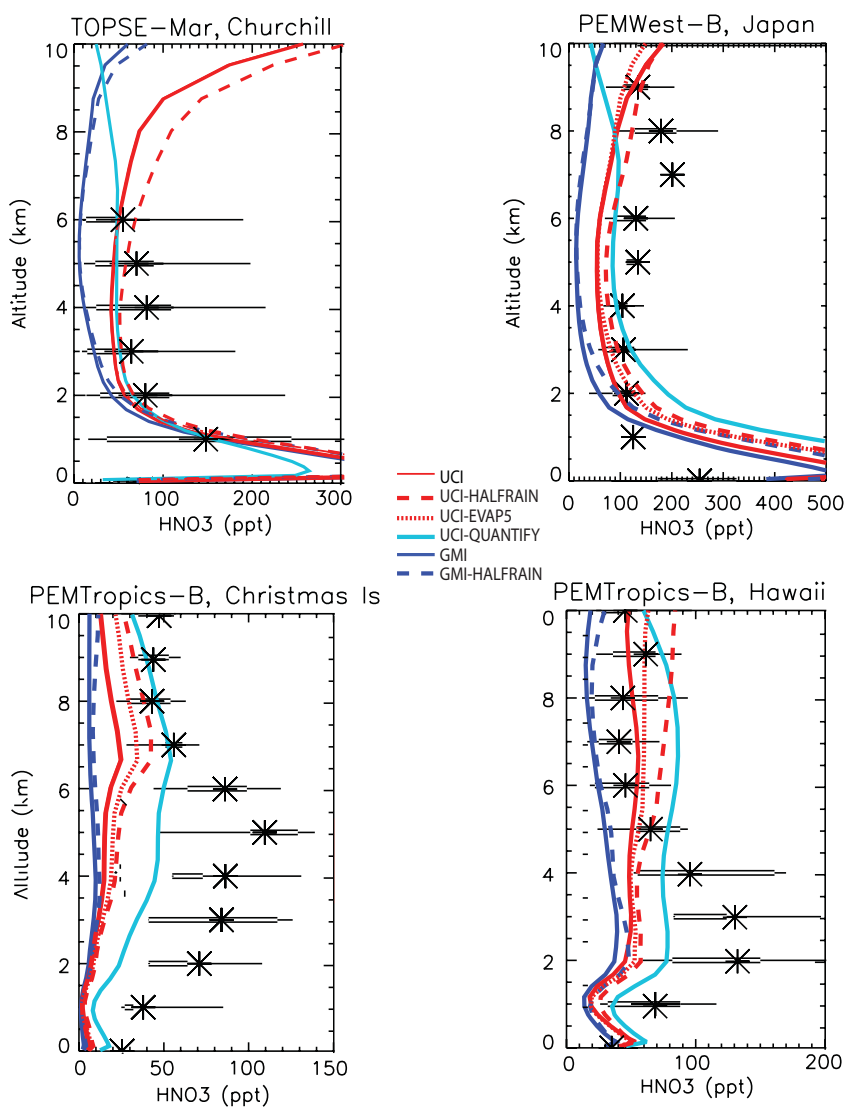

Fig. 9. Same as Fig. 2b, n, r, and u, but model profiles are for UCI (red solid), UCI-HALFRAIN (red dashed), UCI-EVAP5 (red dotted), UCI-QUANTIFY (cyan), GMI (blue), and GMI-HALFRAIN (blue dashed), and the range of the $\mathrm{X}$-axis has been decreased to highlight the differences between the simulations.

As discussed in Sect. 4.1.1, the $\mathrm{HNO}_{3}$ abundance is determined primarily by the balance between $\mathrm{NO}_{\mathrm{x}}$ sources and removal by precipitation. The results from the UCIQUANTIFY simulations show that the relationship between the spatial distribution of $\mathrm{NO}_{\mathrm{x}}$ sources and the spatial distribution of removal is indeed critical, with large increases in the $\mathrm{HNO}_{3}$ abundance for the PEMTropics-B profiles in particular. The QUANTIFY emissions in fact greatly improve agreement with all of the PEMTropics-B profiles (not shown), which had the worst agreement with the UCI control simulation.

\section{Summary and discussion}

Scavenging is a highly complex process that depends on the spatial distribution of clouds, the overlap between condensate and precipitation, and the exchange of mass between clouds and the environment, as well as on the details of the microphysical processes of precipitation formation, growth, and evaporation. This complexity requires parameterization 
even in cloud-resolving models, which can at least separate the microphysical process in cloudy and clear regions and fully resolve the exchange between them. The UCI scavenging treatment represents a step toward capturing at least some of the sub-gridscale variability in scavenging in global CTMs, given the typical inputs of gridbox-averaged precipitation rate, cloud condensate, and cloud fraction. The partitioning of the precipitation into subgrid fractions is based on reasonable microphysical assumptions and is generally consistent with the JK00 precipitation parameterization in the ECMWF Integrated Forecast System, and it can be greatly improved if additional microphysical output (for example, evaporation or accretion rates) is available from the underlying meteorological model. We are, of course, unable to resolve the horizontal exchange between cloudy and clear regions within the gridbox, and the UCI scavenging treatment suffers from the universal problem of depending critically on the timestep since the gridbox is fully mixed at each step.

The UCI scavenging treatment more than doubles the lifetime of $\mathrm{HNO}_{3}$ in the tropical upper troposphere compared to a treatment using a "standard" definition of the scavenging fraction and Henry's Law uptake on ice. The short scavenging lifetime implies that the $\mathrm{HNO}_{3}$ abundance depends on the balance between emissions and removal by precipitation. The UCI treatment provides better overall agreement with a large suite of $\mathrm{HNO}_{3}$ observations than the GMI treatment and in many cases provides a good match to observations, particularly when used in conjunction with updated emissions inventories. The greatest differences between the model and observations are found in the middle troposphere, which may indicate that our formulation of uptake in mixedphase clouds is too efficient. While the observations cannot be used to definitively distinguish between the UCI and GMI treatments, they clearly do not support the simulation with no ice phase removal of $\mathrm{HNO}_{3}$.

The impact of cloud overlap is largest in the tropics, as expected given that it is the region with the most vertical cloud structure. The overlap treatment results in less removal of soluble species than GMI throughout the column. This is due to a combination of the reduction of the rainout fraction at most levels and evaporation in the ambient portion of precipitating levels. The UCI overlap can result in a significantly different vertical distribution of highly soluble tracers than GMI, depending on the convolution between the cloud and precipitation structure and the vertical tracer profile. The overlap treatment gives very large relative increases in $\mathrm{HNO}_{3}$, particularly in the tropics, but the absolute impact is small because the tropical $\mathrm{HNO}_{3}$ abundance is so low. This makes it unlikely that the cloud overlap scheme alone can be tested with observations. Many of the distinctive features resulting from the overlap, such as the increased $\mathrm{NO}_{\mathrm{x}}$ along the flanks of the ITCZ, are too small to be measured in absolute terms. However, cloud overlap impacts may be more important for aerosols with large tropical abundances such as dust and those produced from biomass burning.
The impact of the $\mathrm{KV} 06 \mathrm{HNO}_{3}$ ice uptake is largest in the northern midlatitudes, and is confined to the upper and middle troposphere. While the ice treatment gives much smaller relative increases in $\mathrm{HNO}_{3}$ than cloud overlap, the absolute impacts are larger because the $\mathrm{HNO}_{3}$ abundances are larger in midlatitudes. The KV06 burial model predicts a minimum in scavenging in the mid-troposphere due to inefficient trapping of gas molecules at warm temperatures. However, the uptake minimum is not necessarily reflected as a local maximum in $\mathrm{HNO}_{3}$ abundance because the profile also depends on the vertical distribution of sources and the vertical structure of precipitation.

Ice phase scavenging also has a large impact on $\mathrm{H}_{2} \mathrm{O}_{2}$ and $\mathrm{HNO}_{4}$ abundances, and both species are more sensitive in absolute terms to the details of the scavenging formulation (UCI vs. GMI) than $\mathrm{HNO}_{3}$. However, the impacts of $\mathrm{H}_{2} \mathrm{O}_{2}$ scavenging on the $\mathrm{O}_{3}$ budget are very small, because $\mathrm{H}_{2} \mathrm{O}_{2}$ is not a major source of $\mathrm{HO}_{\mathrm{x}}$ above the boundary layer. Ice phase scavenging of $\mathrm{HNO}_{4}$, on the other hand, has a much larger impact on $\mathrm{O}_{3}$, and the $\mathrm{O}_{3}$ budget is $\sim 7$ times more sensitive to the differences in $\mathrm{HNO}_{4}$ removal in UCI and GMI than it is to the differences in $\mathrm{HNO}_{3}$ removal.

One desirable feature of the UCI scavenging treatment is that, unlike GMI, the $\mathrm{HNO}_{3}$ abundance responds to changes in the rain rate, since the removal is not saturated. The differences between UCI and GMI are thus likely larger than shown here for other meteorological fields with proper partitioning between convective and large-scale rain. We have also shown that while the specification of the evaporation rate is one of the largest uncertainties in our algorithm, the $\mathrm{HNO}_{3}$ abundance is insensitive to a factor of 5 reduction in the evaporation rate. The parameterization of uptake in mixed-phase clouds is another large uncertainty and, given that the largest differences between the model and measurements are found in the middle troposphere where these clouds are likely to occur, our assumptions for mixed-phase clouds require further investigation. Long et al. (2010) found riming to be the most important removal process in mixed-phase clouds using a cloud-resolving model, while our assumption of relatively efficient rainout renders riming a small fraction of the net removal. While our model-measurement comparisons indicate that the removal by mixed phase clouds may be too efficient, $\mathrm{HNO}_{3}$ removal at very cold temperatures near the tropical tropopause may be underrepresented here. Kärcher et al. (2009) find higher $\mathrm{HNO}_{3}: \mathrm{H}_{2} \mathrm{O}$ molar ratios at very cold temperatures than those predicted by their trapping model, and other studies indicate that freezing of $\mathrm{HNO}_{3}$ aerosol particles may be important in tropical tropopause region (Voigt et al, 2008; Krämer et al., 2008; Chepfer et al., 2007).

\section{Implications}

Ice phase removal of $\mathrm{HNO}_{3}$ is critical to the upper tropospheric $\mathrm{O}_{3}$ budget. We find that the simulation with no ice 
scavenging of $\mathrm{HNO}_{3}$ is not supported by the observations and that it results in very different upper tropospheric chemistry than either the KV06 or Henry's Law ice uptake scenario, with significant decreases in $\mathrm{H}_{2} \mathrm{O}_{2}$ and a $\sim 2.5 \mathrm{DU}$ net increase in tropospheric $\mathrm{O}_{3}$. The details of $\mathrm{HNO}_{3}$ ice phase scavenging, however, are much less critical. The large relative increases in $\mathrm{HNO}_{3}$ in UCI vs GMI have only a small impact on $\mathrm{NO}_{\mathrm{x}}$ and $\mathrm{O}_{3}$, with a global increase in tropospheric $\mathrm{O}_{3}$ of 0.3 DU. The KV06 ice uptake is responsible for almost all of the increase in $\mathrm{NO}_{\mathrm{x}}$ and $\mathrm{O}_{3}$ because it affects $\mathrm{HNO}_{3}$ at midlatitudes, where abundances are relatively large.

While the differences in $\mathrm{O}_{3}$ are small for differences in $\mathrm{HNO}_{3}$ ice phase scavenging, our results indicate that it is crucial to determine whether and, if so, how much, $\mathrm{HNO}_{4}$ is removed from the upper troposphere by ice phase scavenging. It is clear that the $\mathrm{NO}_{\mathrm{x}}-\mathrm{O}_{3}$ cycle is much more sensitive to $\mathrm{HNO}_{4}$ than to $\mathrm{HNO}_{3}$ because of the rapid cycling between $\mathrm{NO}_{\mathrm{x}}$ and $\mathrm{HNO}_{4}$. Additional laboratory studies of $\mathrm{HNO}_{4}$-ice interactions and atmospheric measurements of $\mathrm{HNO}_{4}$ abundances are needed to define its role in controlling tropospheric $\mathrm{NO}_{\mathrm{x}}$ and $\mathrm{O}_{3}$.

Efforts to constrain upper tropospheric sources of $\mathrm{NO}_{\mathrm{x}}$ from lightning and aircraft by combining models and measurements (e.g. Martin et al., 2007) will depend critically on whether ice-phase removal of $\mathrm{NO}_{\mathrm{y}}$ species is included in the model. Failure to represent ice phase scavenging will result in a significant underestimate of the $\mathrm{NO}_{\mathrm{x}}$ source. Furthermore, if $\mathrm{HNO}_{4}$ ice uptake is important, the source constraints may depend more sensitively on the details of the ice removal parameterization.

Our results may seem to indicate that it makes little difference whether one uses a relatively simple scavenging scheme like GMI, with an appropriately chosen retention coefficient to match observations, or the more complex UCI scheme, at least for $\mathrm{HNO}_{3}$. However, the UCI scheme does offer a number of advantages. The structure of the UCI algorithm allows direct input of microphysical parameters such as the evaporation rate, accretion rates for various precipitation types, and autoconversion rates from the underlying meteorological model or from a coupled GCM. In fact, we have recently implemented the UCI scheme in the Community Atmosphere Model with Chemistry (CAM-Chem) and will begin testing differences between using our microphysical assumptions and using the terms directly from the model. Recent studies indicate that the net $\mathrm{HNO}_{3}$ uptake on ice depends strongly on the ice water content of the clouds, which in turn depends on assumptions about ice crystal formation (Krämer et al., 2008; Gensch et al., 2008). With CAM-Chem, we can test the dependence on nucleation and freezing processes. The degree to which the scheme must be modified to accept direct microphysical inputs depends on the level of detail desired. The simplest option is to read in gridbox-average values of the evaporation rate, sum of all accretion rates (e.g. ice accreting snow, snow accreting cloud water,...) and sum of all precipitation generation rates. Using the UCI cloud overlap assumptions, these can be converted into the $p_{\mathrm{NEW}}, \Delta p_{\mathrm{ACC}}$, and evap terms discussed in the Appendix. Mean precipitation diameters could likewise replace $d_{\mathrm{NEW}}$ and $d_{\mathrm{ACC}}$. If the microphysical scheme is more detailed and provides local evaporation, accretion, and precipitation generation rates along with fractional areas for each process, then the subroutine determines only the fraction of dissolved tracer based on the cloud ice/water content, and the removal is calculated using the model-supplied values of, for example, ice accreting snow and the fractional area in which the accretion takes place.

In addition to the advantages of direct microphysical inputs to the UCI algorithm, the structure of the cloud overlap scheme is such that it can be tested against cloud resolving models to determine how well we capture the subgridscale variability in precipitation removal. We have also implemented the UCI scheme in the Weather and Regional Forecasting Model with Chemistry (WRF-Chem), where we can compare simulations at resolutions from $4 \mathrm{~km}$, where the clouds are assumed to be resolved, up to $24 \mathrm{~km}$, using the cloud fractions aggregated from the finer scale simulation. Finally, the UCI treatment responds to changes in the precipitation rate and eliminates the need for arbitrary retention coefficients for reducing the uptake determined by Henry's Law.

While we have not included them here, the UCI treatment is easily extendable to aerosols and the sulfur cycle, as long as the solubility in water and ice are known for the species of interest. The cloud overlap scheme may be much more important for aerosols with large tropical abundances such as mineral dust and biomass burning than it is for $\mathrm{HNO}_{3}$. Aerosols and sulfur species will be incorporated in the CAMChem version of the scheme to determine their sensitivity to the cloud overlap assumptions.

\section{Appendix A}

\section{A1 Precipitation overlap}

Figure A1 is a schematic representation of the overlap scheme provided to assist the reader in following Sects. A1 and A2. Here and in the discussion that follows, model gridbox-average quantities are denoted with capital letters, while derived subgrid quantities are in lower-case. Following the description of the MC, NC, and AM subgrid fractions in Sect. 2, $F_{\mathrm{MC}}$ is the fraction of the gridbox with precipitation from overhead falling through cloud (and thus it may contain a mixture of precipitation from above and precipitation generated in the layer), $F_{\mathrm{NC}}$ is the cloudy fraction of the gridbox with no precipitation overhead (which may contain new precipitation generated in the layer), and $F_{\mathrm{AM}}$ is the fraction of the gridbox with precipitation from overhead falling through clear sky. The remainder of the gridbox, $F_{\mathrm{CS}}$, is clear sky, with no cloud and no precipitation. 


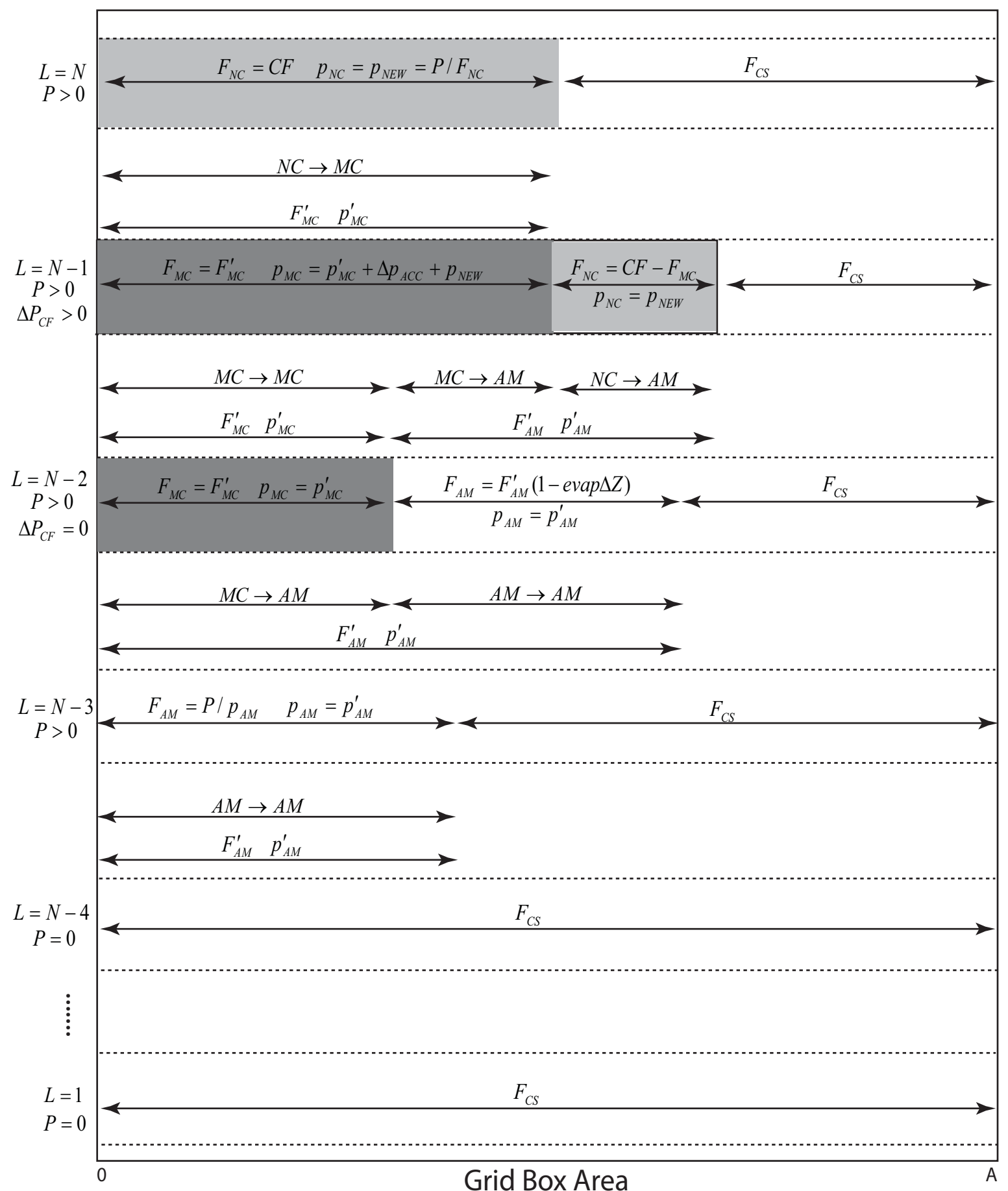

Fig. A1. Schematic of an idealized grid box with $N$ levels, indicated by the horizontal dotted lines. The space between the levels is for illustrative purposes only. Levels $N$ to $N-2$ contain clouds (grey shaded areas) and Levels $N$ to $N-3$ have $P(L)>0$. All gridbox fractions and precipitation rates are defined in the text and are shown for each level. The terms $\mathrm{XX} \rightarrow \mathrm{YY}$ indicate the gridbox fraction corresponding to $\hat{f}_{\mathrm{XX}} \rightarrow \mathrm{YY}$ as defined in the text (Eqs. A3 to A8). Level $N$ is the first precipitating level, and the precipitating fraction and rate are given by Eqs. (A1) and (A21). Level $N-1$ provides an example with $C F(L)>C F(L+1), \Delta P_{C F}>0$ (Eq. A18), and $p_{\mathrm{NEW}}>0$ ( $p_{\mathrm{MC}}$ and $p_{\mathrm{NC}}$ given by Eqs. A27 and A28). Level $N-2$ has $C F(L+1)>C F(L)$ and $\Delta P_{C F}=0$, with the standard evaporation in the ambient region sufficient to account for the decrease in $P$ from level $N-1$ to $N-2$ (Eqs. A16 and A17). Level $N-3$ has $C F(L)=0$ and the decrease in $P$ from level $N-2$ to $N-3$ exceeds the standard evaporation rate (Eq. A17). There is full evaporation of the precipitation in level $N-4$ $(P(L)=0)$. 
By definition, the first precipitating level below a nonprecipitating level has

$F_{\mathrm{NC}}(L)=C F(L)$

$F_{\mathrm{CS}}(L)=1-C F(L)$,

and all other fractions are 0. Proceeding down through the column, we calculate the fraction (denoted as $\hat{f}$ ) of each of the fractional areas MC, NC, and AM that lie over the mixed cloud and ambient air regions of the layer below, assuming maximum cloud overlap for precipitating layers. These fractions are given by:

$$
\begin{aligned}
& \hat{f}_{\mathrm{MC} \rightarrow \mathrm{MC}}=\frac{C F(L-1)}{F_{\mathrm{MC}}(L)} \\
& \hat{f}_{\mathrm{MC} \rightarrow \mathrm{AM}}=1-\hat{f}_{\mathrm{MC} \rightarrow \mathrm{MC}} \\
& \hat{f}_{\mathrm{NC} \rightarrow \mathrm{MC}}=\frac{C F(L-1)-F_{\mathrm{MC}}(L)}{F_{\mathrm{NC}}(L)} \\
& \hat{f}_{\mathrm{NC} \rightarrow \mathrm{AM}}=1-\hat{f}_{\mathrm{NC} \rightarrow \mathrm{MC}} \\
& \hat{f}_{\mathrm{AM} \rightarrow \mathrm{MC}}=1-\hat{f}_{\mathrm{AM} \rightarrow \mathrm{AM}} \\
& \hat{f}_{\mathrm{AM} \rightarrow \mathrm{AM}}=\frac{C F(L)+F_{\mathrm{AM}}(L)-C F(L-1)}{F_{\mathrm{AM}}(L)}
\end{aligned}
$$

Where the symbols $\rightarrow$ MC and $\rightarrow$ AM indicate the fractions of level $L$ overlying the mixed cloud and ambient fractions in level $L-1$, respectively. For Eqs. (A3)-(A8), $\hat{f}_{\mathrm{XX} \rightarrow \mathrm{YY}}=\min \left(1, \max \left(0, \hat{f}_{\mathrm{XX} \rightarrow \mathrm{YY}}\right)\right)$ and $\sum_{\mathrm{YY}} \hat{f}_{\mathrm{XX} \rightarrow \mathrm{YY}}=1$. Both the fraction above mixed cloud and the fraction above ambient are 0 for any subgrid fraction with $F(L)=0$. Since $F_{\mathrm{NC}}(L-1)>0$ only if the cloud fraction is greater than the precipitating fraction of level $L\left(\sum F_{\mathrm{XX}}(L)\right), \hat{f}_{\mathrm{XX} \rightarrow \mathrm{NC}}=0$ for all $F_{\mathrm{XX}}(L)$.

The total fraction of the gridbox with precipitation falling into the mixed cloud fraction in the level below is then given by

$$
\begin{aligned}
& F_{\mathrm{MC}}^{\prime}(L-1)=F_{\mathrm{MC}}(L) \cdot \hat{f}_{\mathrm{MC} \rightarrow \mathrm{MC}}+F_{\mathrm{NC}}(L) \cdot \hat{f}_{\mathrm{NC} \rightarrow \mathrm{MC}} \\
& \quad+F_{\mathrm{AM}}(L) \cdot \hat{f}_{\mathrm{AM} \rightarrow \mathrm{MC}},
\end{aligned}
$$

and the precipitation rate falling into mixed cloud $\left(p_{\mathrm{MC}}^{\prime}\right)$ is calculated from

$$
\begin{aligned}
& p_{\mathrm{MC}}^{\prime}(L-1) F_{\mathrm{MC}}^{\prime}(L-1)=p_{\mathrm{MC}}(L) \cdot F_{\mathrm{MC}}(L) \cdot \hat{f}_{\mathrm{MC} \rightarrow \mathrm{MC}} \\
& \quad+p_{\mathrm{NC}}(L) \cdot F_{\mathrm{NC}}(L) \cdot \hat{f}_{\mathrm{NC} \rightarrow \mathrm{MC}} \\
& \quad+p_{\mathrm{AM}}(L) \cdot F_{\mathrm{AM}}(L) \cdot \hat{f}_{\mathrm{AM} \rightarrow \mathrm{MC}}
\end{aligned}
$$

where $p_{\mathrm{MC}}, p_{\mathrm{NC}}$, and $p_{\mathrm{AM}}$ are the local precipitation rates in $\mathrm{MC}, \mathrm{NC}$, and $\mathrm{AM}$, which are discussed in more detail below. The prime symbols indicate that these are top-ofthe-layer values for layer $L-1$ that are adjusted within the layer as discussed in Appendix A2. We average the diameter of the precipitation falling into mixed cloud or ambient air, so that only a single diameter falls into each region. The precipitation-rate weighted average diameter of precipitation falling into mixed cloud below is derived from

$$
\begin{aligned}
d_{\mathrm{MC}}^{\prime} & (L-1) p_{\mathrm{MC}}^{\prime}(L-1) \cdot F_{\mathrm{MC}}^{\prime}(L-1) \\
& =d_{\mathrm{MC}}(L) \cdot p_{\mathrm{MC}}(L) \cdot F_{\mathrm{MC}}(L) \cdot \hat{f}_{\mathrm{MC} \rightarrow \mathrm{MC}} \\
& +d_{\mathrm{NC}}(L) \cdot p_{\mathrm{NC}}(L) \cdot F_{\mathrm{NC}}(L) \cdot \hat{f}_{\mathrm{NC} \rightarrow \mathrm{MC}} \\
& +d_{\mathrm{AM}}(L) \cdot p_{\mathrm{AM}}(L) \cdot F_{\mathrm{AM}}(L) \cdot \hat{f}_{\mathrm{AM} \rightarrow \mathrm{MC}}
\end{aligned}
$$

The gridbox fraction, precipitation rate, and precipitation diameter of the ambient air in the level below are given respectively by:

$$
\begin{aligned}
& F_{\mathrm{AM}}^{\prime}(L-1)=C F(L)+F_{\mathrm{AM}}(L)-C F(L-1) \\
& p_{\mathrm{AM}}^{\prime}(L-1) F_{\mathrm{AM}}^{\prime}(L-1) \\
& \quad=p_{\mathrm{MC}}(L) \cdot F_{\mathrm{MC}}(L) \cdot \hat{f}_{\mathrm{MC} \rightarrow \mathrm{AM}} \\
& \quad+p_{\mathrm{NC}}(L) \cdot F_{\mathrm{NC}}(L) \cdot \hat{f}_{\mathrm{NC} \rightarrow \mathrm{AM}} \\
& \quad+p_{\mathrm{AM}}(L) \cdot F_{\mathrm{AM}}(L) \cdot \hat{f}_{\mathrm{AM} \rightarrow \mathrm{AM}} \\
& \\
& d_{\mathrm{AM}}^{\prime}(L-1) p_{\mathrm{AM}}^{\prime}(L-1) \cdot F_{\mathrm{AM}}^{\prime}(L-1) \\
& \quad=d_{\mathrm{MC}}(L) \cdot p_{\mathrm{MC}}(L) \cdot F_{\mathrm{MC}}(L) \cdot \hat{f}_{\mathrm{MC} \rightarrow \mathrm{AM}} \\
& \quad+d_{\mathrm{NC}}(L) \cdot p_{\mathrm{NC}}(L) \cdot F_{\mathrm{NC}}(L) \cdot \hat{f}_{\mathrm{NC} \rightarrow \mathrm{AM}} \\
& \quad+d_{\mathrm{AM}}(L) \cdot p_{\mathrm{AM}}(L) \cdot F_{\mathrm{AM}}(L) \cdot \hat{f}_{\mathrm{AM} \rightarrow \mathrm{AM}} .
\end{aligned}
$$

Given the rate and diameter of the incoming precipitation from the level above and the gridbox-average precipitation rate $(P(L))$ in each layer, we calculate the precipitation rate and diameter for each subgrid fraction as discussed below.

\section{A2 Treatment of precipitation}

We assume a constant rate of evaporation in ambient air (evap $=25 \% \mathrm{~km}^{-1}$ for the control run) and reduce $F_{\mathrm{AM}}$ while keeping the local precipitation rate, $p_{\mathrm{AM}}$, constant:

$F_{\mathrm{AM}}(L)=\max \left(0, F_{\mathrm{AM}}^{\prime}(L) \cdot(1-\right.$ evap $\left.\cdot \Delta Z)\right)$

$p_{\mathrm{AM}}(L)=p_{\mathrm{AM}}^{\prime}(L)$

where $\Delta Z$ is the thickness of the layer. We assume full evaporation of the precipitation, so that the remaining precipitation does not change diameter $\left(d_{\mathrm{AM}}(L)=d_{\mathrm{AM}}^{\prime}(L)\right)$. The choice of $25 \% \mathrm{~km}^{-1}$ is arbitrary and reflects the fact that precipitation often falls some distance, but not many kilometers, through clear sky. We test the sensitivity to evap as discussed in Sect. 4.4 and find it to be very small in most regions.

If there is no cloud in the layer and the gridbox-average ambient precipitation rate $\left(p_{\mathrm{AM}} F_{\mathrm{AM}}\right)$ is greater than $P(L)$, then we further reduce the ambient area so that

$$
F_{\mathrm{AM}}(L)=P(L) / p_{\mathrm{AM}}(L) .
$$


If there is no cloud in the layer and $p_{\mathrm{AM}}(L) F_{\mathrm{AM}}(L)<$ $P(L)$, we reduce the evaporation rate to its minimum value $\left(\right.$ evap $_{\min }=5 \% \mathrm{~km}^{-1}$ for the control run) and recalculate $F_{\mathrm{AM}}$. If $p_{\mathrm{AM}}(L) F_{\mathrm{AM}}(L)<P(L)$ even with minimal evaporation, then we assume that there must be a cloud collocated with the precipitation in the layer since precipitation is being generated, and we impose a $10 \%$ cloud fraction (prior to determining the overlap between the layer above and layer $L$ as described in Appendix A1). The value of $10 \%$ was chosen to provide numerical stability while having minimal impact on the removal.

If there is a cloud in the layer, then the grid-box average change in precipitation rate within the cloud fraction $\left(C F(L)=F_{\mathrm{NC}}(L)+F_{\mathrm{MC}}(L)\right)$ is given by:

$$
\begin{gathered}
\Delta P_{C F}(L)=P(L)-p_{\mathrm{AM}}(L) \cdot F_{\mathrm{AM}}(L) \\
-p_{\mathrm{MC}}^{\prime}(L) \cdot F_{\mathrm{MC}}^{\prime}(L) .
\end{gathered}
$$

The mixed cloud fraction does not change, so $F_{\mathrm{MC}}=F_{\mathrm{MC}}^{\prime}$. If the cloud fraction in the layer is larger than $F_{\mathrm{MC}}$ then $F_{\mathrm{NC}}(L)=\max \left(0, C F(L)-F_{\mathrm{MC}}(L)\right)$. The distribution of $\triangle P_{C F}$ between $\mathrm{MC}$ and $\mathrm{NC}$ is determined as described below.

If $\Delta P_{C F} \leq 0$, there can be no generation of new precipitation, so $p_{\mathrm{NC}}=0$ and $d_{\mathrm{NC}}=0$. We apportion as much of $P(L)$ as possible into $F_{\mathrm{MC}}$, so that $p_{\mathrm{MC}}(L)=$ $\min \left(p_{\mathrm{MC}}^{\prime}(L), P(L) / F_{\mathrm{MC}}(L)\right)$. If the precipitation rate for the layer is large enough that $P(L) / F_{\mathrm{MC}}(L)>p_{\mathrm{MC}}^{\prime}(L)$, but the sum of the MC and AM precipitation is less than $P(L)$, then we evaporate additional area from AM, while keeping the local precipitation rate constant, to match the out-ofcloud precipitation:

$F_{\mathrm{AM}}(L)=\left(\max \left(0, P(L)-p_{\mathrm{MC}}(L) \cdot F_{\mathrm{MC}}(L)\right)\right) / p_{\mathrm{AM}}(L)$.

If, on the other hand, $0<P(L) / F_{\mathrm{MC}}(L)<p_{\mathrm{MC}}^{\prime}$, there is total evaporation in the ambient air and partial evaporation in the cloud. We assume that partial evaporation decreases the size of frozen precipitation, such that

$d_{\mathrm{MC}}(L)=\left(\frac{p_{\mathrm{MC}}(L)}{p_{\mathrm{MC}}^{\prime}(L)}\right)^{1 / 3} \cdot d_{\mathrm{MC}}^{\prime}(L)$

(assuming spherical hydrometeors). For liquid precipitation, we assume full evaporation of a fraction of the raindrops. If $P(L)=0$, then there is complete evaporation in both the cloud and the ambient and $d_{\mathrm{MC}}=d_{\mathrm{AM}}=0$.

If $\Delta P_{C F}>0$, then the in-cloud precipitation rate increases by a combination of accretion by precipitation falling through $\mathrm{MC}$ and new precipitation generation throughout the cloud fraction $\left(C F(L)=F_{\mathrm{NC}}(L)+F_{\mathrm{MC}}(L)\right)$. The rate constant for accretion is given by the integration of the continuous-collection equation over the Marshall-Palmer size distribution for snow (Gunn and Marshall, 1958) or rain (Marshall and Palmer, 1948) (Lin, 1983; Lohmann and Roeckner, 1996; Rotstayn, 1997), as described below. We assume that new precipitation generation occurs only if the increase in the precipitation rate due to accretion is less than $\Delta P_{C F}$, or if $F_{\mathrm{MC}}=0$. For the first precipitating layer below a non-precipitating layer, all of the precipitation is assumed to form within the cloud, so that

$p_{\mathrm{NC}}=\frac{P(L)}{F_{\mathrm{NC}}}$

\section{A2.1 Frozen precipitation}

For $T<273 \mathrm{~K}$, we calculate not only the increase in precipitation rate due to accretion, but also the growth of snow resulting from riming of cloud ice and water. The tracer removal rate decreases as the average precipitation diameter increases. We assume that precipitation is frozen below $273 \mathrm{~K}$, even though mixed phase clouds exist between $240 \mathrm{~K}$ and $273 \mathrm{~K}$ in the ECMWF meteorological fields. Thus, we use the total condensed cloud water in the equations for accretion and particle growth.

The rate of change of the cloud condensed phase mixing ratio for ice water $\left(q_{\mathrm{i}}\right)$ and liquid water $\left(q_{1}\right)$ due to accretion is given by:

$\frac{d\left(q_{\mathrm{i}}+q_{1}\right)}{\mathrm{d} t}=-\frac{E_{\mathrm{AC}} \Lambda_{\mathrm{s}}}{2 \rho_{\mathrm{s}}} \frac{S}{A}\left(q_{\mathrm{i}}+q_{1}\right)$

(Rotstayn, 1997) where $E_{\mathrm{AC}}$ is the mean value of the collection efficiency for accretion, $\Lambda_{\mathrm{s}}$ is the slope factor of the Marshall-Palmer distribution, $\rho_{\mathrm{S}}$ is the bulk density of snow (100 $\mathrm{kg} \mathrm{m}^{-3}$, Rotstayn, 1997), $S$ is the gridbox-averaged snowfall rate $\left(\mathrm{kg} \mathrm{s}^{-1}\right)$, and $A$ is the gridbox area in which accretion is occuring. We use a single collection efficiency for accretion of cloud ice and water by snow $\left(E_{\mathrm{ACs}}\right)$, taken from Lohmann and Roeckner (1996):

$E_{\mathrm{ACs}}=\exp (0.025(T-273 \mathrm{~K}))$.

Field and Heymsfield (2002, henceforth FH02) show that $\Lambda_{\mathrm{s}}=1 / \bar{D}$, the average diameter of a self-scaling particle size distribution that evolves via aggregation. Substituting $1 / d_{\mathrm{MC}}^{\prime}$ for $\Lambda_{\mathrm{S}}$ and $p_{\mathrm{MC}}^{\prime}$ for $S / A$, the ice and liquid water content $\left(\mathrm{kg} \mathrm{m}^{-3}\right)$ taken up by accretion within $F_{\mathrm{MC}}$ is:

$$
\begin{array}{r}
\Delta(i w c+l w c)_{\mathrm{ACC}}=\min \left(\rho\left(q_{\mathrm{i}}+q_{1}\right) \cdot \frac{F_{\mathrm{MC}}}{F_{\mathrm{MC}}+F_{\mathrm{NC}}}\right. \\
\left.\cdot\left(1-\exp \left(-\frac{E_{\mathrm{ACs}}}{2 \rho_{\mathrm{s}} d_{\mathrm{MC}}^{\prime}} p_{\mathrm{MC}}^{\prime} \Delta t\right)\right), \frac{\Delta P_{C F} \Delta t}{\Delta Z}\right)
\end{array}
$$

The accretion is limited by the total precipitation generated in the cloud, $\Delta P_{C F} \Delta t$, divided by the thickness of the layer.

The change in the local precipitation rate due to accretion is

$\Delta p_{\mathrm{ACC}}=\frac{\Delta(i w c+l w c)_{\mathrm{ACC}} \Delta Z}{F_{\mathrm{MC}} \Delta t}$.

Assuming spherical hydrometeors, the diameter of the rimed precipitation increases to

$d_{\mathrm{ACC}}=\left(\frac{p_{\mathrm{MC}}^{\prime}+\Delta p_{\mathrm{ACC}}}{p_{\mathrm{MC}}^{\prime}}\right)^{1 / 3} \cdot d_{\mathrm{MC}}^{\prime}$ 
If $\Delta p_{\mathrm{ACC}} \cdot F_{\mathrm{MC}}<\Delta P_{C F}$, then new precipitation is formed in the layer, with precipitation rate $p_{\mathrm{NEW}}=$ $\left(\Delta P_{C F}-\Delta p_{\mathrm{ACC}} \cdot F_{\mathrm{MC}}\right) / C F$. The $\mathrm{MC}$ and NC precipitation rates are then given by

$p_{\mathrm{MC}}=p_{\mathrm{MC}}^{\prime}+\Delta p_{\mathrm{ACC}}+p_{\mathrm{NEW}}$

$p_{\mathrm{NC}}=p_{\mathrm{NEW}}$

We determine the mean diameter of newly formed frozen hydrometeors using the empirical relationship from $\mathrm{FHO2,}$ which relates the mean diameter of ice particles to the precipitation rate and in-cloud ice water content, based on a large set of observational data:

$d=\left(\frac{i w c \cdot \eta \cdot \Gamma(\theta)}{\alpha \varphi \Gamma(\beta+1)}\right)^{-1 / b}$

Where iwc is the ice water content in $\mathrm{g} \mathrm{m}^{-3}, \varphi=\rho_{\mathrm{w}} p$ $\left(\mathrm{g} \mathrm{cm}^{-2} \mathrm{~s}^{-1}\right)$ is the ice mass flux density (density of liquid water $\times$ precipitation rate), $\theta, \beta, \eta, \alpha$, and $b$ are empirical functions that depend on the precipitation rate, and $\Gamma$ is the gamma function. Using $p_{\text {NEW }}$ as the precipitation rate, we find $d_{\text {NEW }}$ using the FH02 relationship, imposing a minimum diameter of $100 \mu \mathrm{m}$. The diameter of $\mathrm{NC}$ precipitation is then $d_{\mathrm{NC}}=d_{\mathrm{NEW}}$.

The precipitation in the MC portion of the gridbox is assumed to be a mixture of rimed and newly formed precipitation. We calculate the precipitation-rate-weighted average of $d_{\mathrm{ACC}}$ and $d_{\mathrm{NEW}}$ and compare it to the mean diameter from FH02, $d_{\mathrm{MC}_{\mathrm{FH}}}$, using $p_{\mathrm{MC}}$ as the precipitation rate. $d_{\mathrm{MC}}$ is then taken to be the larger of the two values. If $d_{\mathrm{MC}}$ is larger than the weighted average of $d_{\mathrm{ACC}}$ and $d_{\mathrm{NEW}}$, we assume that additional aggregation of snow shifts the particle size distribution toward a larger mean diameter.

\section{A2.2 Liquid precipitation}

For liquid water clouds, we calculate the change in precipitation rate due to accretion, but do not explicitly determine any change in raindrop diameter, since collision of droplets generally results in droplet shattering with little change in the size distribution (Srivastava, 1971). For rain, the slope factor of the Marshall-Palmer distribution can be related to the rain rate, so that

$\frac{\mathrm{d} q_{1}}{\mathrm{~d} t}=-0.24 E_{\mathrm{ACr}}\left(\frac{R}{A}\right)^{3 / 4} q_{1}$

where $q_{1}$ is the mixing ratio of liquid water, $E_{\mathrm{ACr}}=0.7$ is the collection efficiency for rain accreting cloud water (Rotstayn, 1997), and $R$ is the gridbox-averaged rain rate $\left(\mathrm{kg} \mathrm{s}^{-1}\right)$ (Rotstayn, 1997).

Substituting $p_{\mathrm{MC}}^{\prime}$ for $R / A$, the liquid water content taken up by accretion is:

$$
\begin{aligned}
& \Delta l w c_{\mathrm{ACC}}=\min \left(\rho q_{1} \cdot \frac{F_{\mathrm{MC}}}{F_{\mathrm{MC}}+F_{\mathrm{NC}}}\right. \\
& \left.\left(1-\exp \left(-0.24 E_{\mathrm{ACr}} p_{\mathrm{MC}}^{\prime 3 / 4} \Delta t\right)\right), \frac{\Delta P_{C F} \Delta t}{\Delta Z}\right) .
\end{aligned}
$$

and the change in precipitation rate due to accretion is

$$
\Delta p_{\mathrm{ACC}}=\frac{\Delta l w c_{\mathrm{ACC}} \Delta Z}{F_{\mathrm{MC}} \Delta t} .
$$

The rain rate for newly formed precipitation is again $p_{\mathrm{NEW}}=$ $\left(\Delta P_{C F}-\Delta p_{\mathrm{ACC}} \cdot F_{\mathrm{MC}}\right) / C F$, and $p_{\mathrm{MC}}$ and $p_{\mathrm{NC}}$ are as given above.

\section{A3 Scavenging}

The amount of tracer $X(\mathrm{~kg})$ scavenged during timestep $\Delta t$ is given by:

$X_{\mathrm{SCAV}}=X_{o} F_{\mathrm{SCAV}}(1-\exp (-\lambda \Delta t))$,

where $X_{o}$ is the total mass of tracer in the gridbox, $F_{\mathrm{SCAV}}$ is the fraction of the gridbox being scavenged, and $\lambda\left(\mathrm{s}^{-1}\right)$ is the loss rate. We assume that new precipitation is formed homogenously throughout the local cloud fraction, so that $F_{\mathrm{SCAV}}=C F\left(=F_{\mathrm{MC}}+F_{\mathrm{NC}}\right)$. Accretion and scavenging of interstitial air occurs only in the MC fraction of the gridbox, with $F_{\mathrm{SCAV}}=F_{\mathrm{MC}}$, and scavenging of ambient air takes place in the AM fraction, with $F_{\mathrm{SCAV}}=F_{\mathrm{AM}}$. The loss rate for each process is discussed below.

The net loss in each region is given by:

$$
\begin{aligned}
& \chi_{\mathrm{SCAVMC}}=\chi_{\mathrm{NP}} \frac{F_{\mathrm{MC}}}{C F}+\chi_{\mathrm{ACC}}+\chi_{\mathrm{WMC}}-\chi_{\mathrm{EVAPMC}} \\
& \chi_{\mathrm{SCAVNC}}=\chi_{\mathrm{NP}} \frac{F_{\mathrm{NC}}}{C F} \\
& \chi_{\mathrm{SCAVAM}}=\chi_{\mathrm{WAM}}-\chi_{\mathrm{EVAPAM}}
\end{aligned}
$$

where $\chi_{\mathrm{NP}}$ is scavenging by new precipitation formation, $\chi_{\mathrm{ACC}}$ is scavenging by accretion, $\chi_{\mathrm{WMC}}$ and $\chi_{\text {WAM }}$ are washout from interstitial air in $\mathrm{MC}$ and ambient air in AM, and $\chi_{\text {EVAPMC }}$ and $\chi_{\text {EVAPAM }}$ are evaporation in MC and AM. The tracer masses carried into the cloudy and ambient regions of the gridbox below are then:

$$
\begin{aligned}
& \chi_{\mathrm{SCAVMC}}^{\prime}(L-1) \\
& \quad=\left(\chi_{\mathrm{SCAVMC}}^{\prime}(L)+\chi_{\mathrm{SCAVMC}}(L)\right) \cdot \hat{f}_{\mathrm{MC} \rightarrow \mathrm{MC}} \\
& \quad+\chi_{\mathrm{SCAVNC}}(L) \cdot \hat{f}_{\mathrm{NC} \rightarrow \mathrm{MC}} \\
& \quad+\left(\chi_{\operatorname{SCAVAM}}^{\prime}(L)+\chi_{\operatorname{SCAVAM}}(L)\right) \cdot \hat{f}_{\mathrm{AM} \rightarrow \mathrm{MC}} \\
& \\
& \chi_{\mathrm{SCAVAM}}^{\prime}(L-1) \\
& \quad=\left(\chi_{\mathrm{SCAVMC}}^{\prime}(L)+\chi_{\mathrm{SCAVMC}}(L)\right) \cdot \hat{f}_{\mathrm{MC} \rightarrow \mathrm{AM}} \\
& \quad+\chi_{\mathrm{SCAVNC}}(L) \cdot \hat{f}_{\mathrm{NC} \rightarrow \operatorname{AM}} \\
& \quad+\left(\chi_{\mathrm{SCAVAM}}^{\prime}(L)+\chi_{\mathrm{SCAVAM}}(L)\right) \cdot \hat{f}_{\mathrm{AM} \rightarrow \mathrm{AM}} .
\end{aligned}
$$

where the prime symbols indicate the scavenged tracer mass carried in the precipitation at the top of each layer. Note that $\chi_{\mathrm{SCAVMC}}$ and $\chi_{\mathrm{SCAVAM}}$ can be negative if evaporation dominates. 


\section{A3.1 New precipitation formation}

We assume that the cloud ice and liquid water content remain in steady state throughout the model time step, so that they are not reduced by accretion or precipitation formation. The tracer removed by new precipitation formation, $\chi_{\mathrm{NP}}$, is given by Eq. (A33), with the scavenging loss rate dependent on the fraction of tracer dissolved in the liquid phase and the rate of conversion of cloud liquid water to precipitation:

$\lambda_{\mathrm{NP}}=\frac{p_{\mathrm{NEW}}}{(i w c+l w c) \cdot \Delta Z} \frac{\chi_{\mathrm{DIS}}^{*}}{\chi_{\mathrm{MC}}+\chi_{\mathrm{NC}}}$.

where $\chi_{\mathrm{MC}}$ and $\chi_{\mathrm{NC}}$ are the initial tracer masses in the MC and $\mathrm{NC}$ portions of the gridbox. We limit the amount of tracer dissolved in the ice or liquid phase by the total in-cloud tracer mass, $\chi_{\mathrm{MC}}+\chi_{\mathrm{NC}}=\chi_{C F}\left(=X_{o} \cdot C F\right)$, so that

$\chi_{\text {DIS }}^{*}=\frac{\chi_{\text {DIS }} \cdot \chi_{C F}}{\chi_{\text {DIS }}+\chi_{C F}}$

where $\chi_{\text {DIS }}$ is the dissolved tracer mass as determined by Henry's Law equilibrium for the liquid phase and by the KV06 relationship for the molar $\chi: \mathrm{H}_{2} \mathrm{O}$ ratio per ice particle for the ice phase.

For ice clouds,

$\chi_{\mathrm{DISi}}=\mu(T) \cdot i w c \cdot v_{C F} \frac{m_{\chi}}{m_{w}}$,

where $\mu(T)$ is the $\chi: \mathrm{H}_{2} \mathrm{O}$ molar ratio per ice particle, $v_{C F}$ is the cloud volume $\left(\mathrm{m}^{3}\right), m_{\chi}$ is the molecular mass of $\chi\left(\mathrm{kg} \mathrm{mol}^{-1}\right)$, and $m_{w}$ is the molecular mass of $\mathrm{H}_{2} \mathrm{O}$. For $\mathrm{HNO}_{3}, \mu(T)$ is determined by an empirical fit to Fig. 1 of $\mathrm{KV} 06$,

$\mu(T)=\exp \left(-14.2+1.6 \times 10^{-1} \cdot T-7.2 \times 10^{-4} \cdot T\right)$

The mass of $\chi$ dissolved in the liquid phase is

$\chi_{\mathrm{DISl}}=H^{*}(T) \cdot l w c \cdot v_{C F} \cdot \dot{p}_{\chi} \cdot m_{\chi}$,

where $H^{*}(T)\left(\mathrm{moll}^{-1} \mathrm{~atm}^{-1}\right)$ is the temperature-dependent Henry's Law constant, adjusted to account for dissociation in the aqueous phase, $\dot{p}_{\chi}$ is the partial pressure of $\chi$ (atm) and $m_{\chi}$ is the molecular mass of $\chi$.

For mixed phase clouds at $240 \mathrm{~K}<T<258 \mathrm{~K}$, we assume that the entire cloud is glaciated due to the BergeronFindeisen mechanism, and we use $\chi_{\mathrm{DISi}}$ with $i w c$ replaced by $i w c+l w c$. However, $\mu(T)$ is essentially zero above $\sim 240 \mathrm{~K}$ since surface kinetics make trapping during ice crystal growth very inefficient at warm temperatures (Kärcher and Voigt, 2006). For $258 \mathrm{~K}<T<273 \mathrm{~K}$, where we assume that the cloud is still glaciated but that ice crystals form from freezing of supercooled liquid water, we use $R_{\chi} \cdot \chi_{\text {DISl }}$ (with $i w c+l w c$ replacing $l w c$ ) for the amount of tracer dissolved in cloud ice, where $R_{\chi}=0.5$ is a retention coefficient.

\section{A3.2 Accretion}

The mass of $\chi$ removed by accretion, $\chi_{\mathrm{ACC}}$, is proportional to the accreted ice or liquid water content. The loss rate for removal by snow accretion is given by (cf. Eq. A22):

$\lambda_{\mathrm{ACC}}=\frac{E_{\mathrm{ACs}}}{2 \rho_{\mathrm{S}} d_{\mathrm{MC}}^{\prime}} \cdot p_{\mathrm{MC}}^{\prime} \cdot \frac{\chi_{\mathrm{DIS}}^{*}}{\chi_{\mathrm{MC}}}$,

while the loss rate for rain accretion is given by (cf. Eq. A30):

$\lambda_{\mathrm{ACC}}=\left(0.24 E_{\mathrm{ACl}} p^{\prime}{ }_{\mathrm{MC}}^{3 / 4}\right) \cdot \frac{\chi_{\mathrm{DIS}}^{*}}{\chi_{\mathrm{MC}}}$.

In this case, $\chi_{\mathrm{DIS}}^{*}=\frac{\chi_{\mathrm{DIS}} \cdot \chi_{\mathrm{MC}}}{\chi_{\mathrm{DIS}}+\chi_{\mathrm{MC}}}$ where $\chi_{\mathrm{DIS}}$ is calculated as above using the water and tracer content in MC. The total uptake is limited by the amount of tracer that could be dissolved in the maximum possible amount of accreted water, $\frac{\Delta P_{C F} \Delta t}{\Delta Z}$.

\section{A3.3 Washout in interstitial and ambient air}

We can model the scavenging of gases in the pathway of falling hydrometeors using the same equation as for accretion, with the appropriate collection efficiency for gases or aerosols (Rotstayn and Lohmann, 2002). However, the collection efficiency for impaction scavenging of gases by snow is unknown. Alheit et al. (1990) show that impaction scavenging of aerosols by snow is a far less efficient scavenging mechanism than new snow formation and accretion. Rotstayn and Lohmann (2002) use a value of 0.01 for scavenging of aerosols by snow, based on Jylha (1999), which is a factor of 10 smaller than the collection efficiency for accretion. Given that we expect impaction scavenging by ice to be small compared to accretion and have no formalism for modeling how gases removed by impaction might be buried during the riming process, we do not attempt to represent scavenging of gases in interstitial air by snow. In ambient air, the air is subsaturated with respect to ice, so there can be no ice growth and no burial of gases. While it is possible that $\mathrm{HNO}_{3}$ may stick to the outer surface of the ice at very low temperatures, we expect the total removal to be negligible.

For aerosols and highly soluble gases, scavenging in interstitial and ambient air is kinetically limited. Since impact scavenging is determined by the area swept out by falling rain drops, we use the same scavenging rate as for accretion of cloud water by rain, with appropriate collection efficiencies for aerosols (collision-limited) and highly soluble gases (mass-transfer limited) (Rotstayn and Lohmann, 2002) (cf. Eq. A30):

$\lambda_{\mathrm{W}}=-0.24 E_{\mathrm{C} \chi} p^{3 / 4}$

where $p=p_{\mathrm{MC}}^{\prime}$ (the precipitation entering the top of MC) if $\Delta P_{C F}>0$ and $p=p_{\mathrm{MC}}$ (the precipitation leaving the bottom of MC) if $\Delta P_{C F} \leq 0$ for washout in MC. $p=p_{\mathrm{AM}}$ for washout in AM. We use a collection efficiency of 0.05 for both aerosols and gases, which gives approximately the same 
scavenging as a linear washout rate of $0.1 \mathrm{~mm}^{-1}$ (Dana and Hales, 1976; Levine and Schwartz, 1982; Berge, 1993) at rainfall rates below $\sim 20 \mathrm{~mm} \mathrm{day}^{-1}$ (Rotstayn and Lohmann, 2002). Washout in interstitial air in MC applies only to the fraction of tracer remaining in the gas phase after uptake by the liquid phase, and will be negligible for highly soluble gases and aerosols except at very low cloud water content.

Scavenging of moderately-soluble gases in interstitial and ambient air is limited by Henry's Law equilibrium with the falling precipitation. The loss rate is given by

$\lambda_{\mathrm{W}}=p \frac{H^{*} \cdot \dot{p}_{\chi} \cdot m_{\chi}}{\chi}$

where $\chi$ represents the tracer mass in the appropriate fraction of the gridbox and, as above, $p=p_{\mathrm{MC}}^{\prime}$ if $\Delta P_{C F}>0$ and $p=p_{\mathrm{MC}}$ if $\Delta P_{C F} \leq 0$ for washout from interstitial air in $\mathrm{MC}$ and $p=p_{\mathrm{AM}}$ for washout in ambient air. The maximum tracer mass that can be held by the precipitation in each subgrid region is given by $\chi_{\mathrm{W} \text { max }}=\chi_{\mathrm{W}_{\mathrm{W}} \Delta t}$, where $\chi$ and $\lambda_{\mathrm{W}}$ are the gas-phase tracer mass and loss rate chosen for the appropriate portion of the gridbox. If the water can hold additional tracer beyond the mass that entered the gridbox in the precipitation and that taken up by accretion within the gridbox $\left(\chi_{\mathrm{W} \operatorname{maxMC}}>\chi_{\mathrm{SCAVMC}}^{\prime}+\chi_{\mathrm{ACC}}\right)$, then the amount scavenged is given by

$$
\begin{gathered}
\chi \chi_{\mathrm{WMC}}=\left[\min \left(\chi_{\mathrm{MC}}-\chi_{\mathrm{DIS}}^{*}, \chi_{W \operatorname{maxMC}}-\left(\chi_{\mathrm{SCAVMC}}^{\prime}+\chi_{\mathrm{ACC}}\right)\right)\right] \\
\left(1-\exp \left(-\lambda \mathrm{WMC}_{\mathrm{WMC}} \Delta t\right)\right) .
\end{gathered}
$$

where $\chi_{\mathrm{MC}}-\chi_{\mathrm{DIS}}^{*}$ is the portion of $\chi_{\mathrm{MC}}$ not dissolved in the aqueous phase. Likewise, if $\chi_{\mathrm{Wmax}} \mathrm{AM}>\chi_{\mathrm{AM}}^{\prime}$

$$
\begin{gathered}
\chi_{\mathrm{WAM}}=\left[\min \left(\chi_{\mathrm{AM}}, \chi_{\mathrm{WmaxAM}}-\chi_{\mathrm{AM}}^{\prime}\right)\right] \\
\left(1-\exp \left(-\lambda_{\mathrm{WAM}} \Delta t\right)\right)
\end{gathered}
$$

If, on the other hand, $\chi_{\mathrm{Wmax}}$ is less than the tracer mass contained in the precipitation, then $\chi$ must de-gas from the precipitation, with $\chi_{\mathrm{EVAPMC}}=\chi_{\mathrm{MC}}^{\prime}+\chi_{\mathrm{ACC}}-\chi_{\mathrm{WmaxMC}}$ and $\chi_{\text {EVAPAM }}=\chi_{\mathrm{AM}}^{\prime}-\chi_{\mathrm{Wmax} \text { AM }}$.

\section{A3.4 Evaporation}

In AM, $\chi_{\text {EVAP }}$ is proportional to the net evaporation of precipitation. If there is in-cloud evaporation, we have different treatments for frozen and liquid precipitation. For frozen precipitation, we assume that there is minimal diffusion of buried gases within the hydrometeors, i.e. that the gas remains in the layer in which it was initially trapped. Thus, the mass of tracer that evaporates is given by the amount of tracer dissolved in the ice mass that evaporates within the layer, which is proportional to the decrease in precipitation rate:

$\Delta i w c_{\mathrm{EVAP}}=\left(p_{\mathrm{MC}}^{\prime}-p_{\mathrm{MC}}\right) F_{\mathrm{MC}} \frac{\Delta t}{\Delta Z}$

Following Eq. (A41), $\chi_{\text {MCEVAP }}$ is given by

$\chi_{\mathrm{MCEVAP}}=\min \left(\chi_{\mathrm{MC}}^{\prime}, \mu(T) \cdot \Delta i w c_{\mathrm{EVAP}} \cdot v_{C F} \frac{m_{\chi}}{m_{w}}\right)$
For liquid precipitation, we assume that a fraction of the raindrops fully evaporate, so that

$\chi_{\mathrm{MCEVAP}}=\frac{p_{\mathrm{MC}}^{\prime}-p_{\mathrm{MC}}}{p_{\mathrm{MC}}^{\prime}} \chi_{\mathrm{MC}}^{\prime}$.

Acknowledgements. This research was supported by NSF's Atmospheric Chemistry program (grant ATM-0550234) and NASA's Modeling, Analysis, and Prediction/Global Modeling Initiative program (grants NNG06GB84G and NNX09AJ47G).

Edited by: H. Tost

\section{References}

Abbatt, J. P. D.: Interaction of $\mathrm{HNO}_{3}$ with water-ice surfaces at temperatures of the free troposphere, Geophys. Res. Lett., 24, 1479-1482, 1997.

Alheit, R. R., Flossmann, A. J., and Pruppacher, H. R.: A theoretical study of the wet removal of atmospheric pollutants, part IV: The uptake and redistribution of aerosol particles through nucleation and impaction scavenging by growing cloud drops and ice particles, J. Atmos. Sci, 47, 870-887, 1990.

Balkanski, Y. J., Jacob, D. J., and Gardner, G. M.: Transport and residence times of tropospheric aerosols inferred from a global three-dimensional simulation of ${ }^{210} \mathrm{~Pb}$, J. Geophys. Res, 98, 20573-20586, 1993.

Bartels-Rausch, T., Huthwelker, T., and Ammann, M.: Interaction of PNA with ice surfaces, AGU Fall Meeting, San Francisco, CA, USA, 15-19 December 2008, \#C41C-0547, 2008.

Berge, E.: Coupling of wet scavenging of sulphur to clouds in a numerical weather prediction model, Tellus B, 45, 1-22, 1993.

Bey, I., Jacob, D. J., Yantosca, R. M., Logan, J. A., Field, B. D., Fiore, A. M., Li, Q., Liu, H. Y., Mickley, L. J., and Schultz, M. G.: Global modeling of tropospheric chemistry with assimilated meteorology: Model description and evaluation, J. Geophys. Res., 106, 23073-23095, 2001.

Chepfer H., Minnis, P., Dubuisson, P., Chiriaco, M., Sun-Mack, S., and Riviere, E. D.: Nitric acid particles in cold thick ice clouds observed at global scale: Link with lightning, temperature, and upper tropospheric water vapor, J. Geophys. Res., 112, D05212, doi:10.1029/2005JD006602, 2007.

Collins, W. D.: Parameterization of generalized cloud overlap for radiative calculations in general circulation models, J. Atmos. Sci., 58, 3224-3242, 2001.

Conklin, M. H. and Bales, R. C.: $\mathrm{SO}_{2}$ uptake on ice sphere: Liquid nature of the ice-air interface, J. Geophys. Res., 98, 1685116844, 1993.

Conklin, M. H., Sigg, A., Neftel, A., and Bales, R. C.: Atmosphere snow transfer function for $\mathrm{H}_{2} \mathrm{O}_{2}$ : Microphysical considerations, J. Geophys. Res., 98, 18367-18376, 1993.

Considine, D. B., Bergmann, D. J., and Liu, H.: Sensitivity of Global Modeling Initiative chemistry and transport model simulations of radon-222 and lead-210 to input meteorological data, Atmos. Chem. Phys., 5, 3389-3406, doi:10.5194/acp-5-33892005, 2005.

Crutzen, P. J. and Lawrence, M. G.: The impact of precipitation scavenging on the transport of trace gases: A 3-dimensional model sensitivity study, J. Atmos. Chem., 37, 81-112, 2000. 
Dana, M. T. and Hales, J. M.: Statistical aspects of the washout of polydisperse aerosols, Atmos. Environ., 10, 45-50, 1976.

Duncan, B. N., Strahan, S. E., Yoshida, Y., Steenrod, S. D., and Livesey, N.: Model study of the cross-tropopause transport of biomass burning pollution, Atmos. Chem. Phys., 7, 3713-3736, doi:10.5194/acp-7-3713-2007, 2007.

Emmons, L. K., Hauglustaine, D. A., Muller, J.-F., Carroll, M. A., Brasseur, G. P., Brunner, D., Staehelin, J., Thouret, V., and Marenco, A.: Data composites of airborne observations of tropospheric ozone and its precursors, J. Geophys. Res., 105, 2049720538, 2000.

Field, P. R. and, A. J. Heymsfield: Aggregation and Scaling of Ice Crystal Size Distributions, J. Atmos. Sci., 60, 544-560, 2002.

Gensch, I. V., Bunz, H., Baumgardner, D. G., Christensen, L. E., Fahey, D. W., Herman, R. L., Popp, P. J., Smith, J. B., Troy, R. F., Webster, C. R., Weinstock, E. M., Wilson, J. C., Peter, T., and Krämer, M.: Supersaturations, microphysics and nitric acid partitioning in a cold cirrus cloudobserved during CR-AVE 2006: an observation-modelling intercomparison study, Environ. Res. Lett., 3, 035003, doi:10.1088/1748-9326/3/3/035003, 2008.

Giorgi, F., and Chameides, W. L.: Rainout lifetimes of highly soluble aerosols and gases as inferred from simulations with a general circulation model, J. Geophys. Res., 91, 14367-14376, 1986.

Gunn, K. L. S. and Marshall, J. S.: The distribution with size of aggregate snowflakes, J. Meteorol., 15, 452-461, 1958.

Hauglustaine, D. A., Brasseur, G. P., Walters, S., Rasch, P. J., Muller, J.-F., Emmons, L. K., and Carroll, M. A.: MOZART, a global chemical transport model for ozone and related chemical tracers: 2. Model results and evaluation, J. Geophys. Res., 103, 28291-28335, 1998.

Hoor, P., Borken-Kleefeld, J., Caro, D., Dessens, O., Endresen, O., Gauss, M., Grewe, V., Hauglustaine, D., Isaksen, I. S. A., Jöckel, P., Lelieveld, J., Myhre, G., Meijer, E., Olivie, D., Prather, M., Schnadt Poberaj, C., Shine, K. P., Staehelin, J., Tang, Q., van Aardenne, J., van Velthoven, P., and Sausen, R.: The impact of traffic emissions on atmospheric ozone and $\mathrm{OH}$ : results from QUANTIFY, Atmos. Chem. Phys., 9, 3113-3136, doi:10.5194/acp-9-3113-2009, 2009.

Hsu, J., Prather, M. J., Wild, O., Sundet, J. K., Isaksen, I. S. A., Browell, E. V., Avery, M. A., and Sachse, G. W.: Are the TRACE-P measurements representative of the Western Pacific during March 2001?, J. Geophys. Res., 109, D02314, doi:10.1029/2003JD004002, 2004.

Iribarne, J. V. and Pyshnov, T.: The effect of freezing on the composition of supercooled droplets - I. Retention of $\mathrm{HCl}, \mathrm{HNO}_{3}$, $\mathrm{NH}_{3}$, and $\mathrm{H}_{2} \mathrm{O}_{2}$, Atmos. Environ., 24A, 383-387, 1990.

Jakob, C. and Klein, S.: The role of vertically varying cloud fraction in the parameterization of microphysical processes in the ECMWF model, Q. J. Roy. Meteor. Soc., 125, 941-965, 1999.

Jakob, C. and Klein, S.: A parameterization of the effects of cloud and precipitation overlap for use in general-circulation models, Q. J. Roy. Meteor. Soc., 126, 2525-2544, 2000.

Jylha, K.: Relationship between the scavenging coefficient for pollutants in precipitation and the radar reflectivity factor, 1, Derivation, J. Appl. Meteorol., 38, 1421-1434, 1999.

Kärcher, B. and Basko, M. M.: Trapping of trace gases in growing ice crystals, J. Geophys. Res., 109, D22204, doi:10.1029/2004JD005254, 2004.

Kärcher, B. and Voigt, C.: Formation of nitric acid/water ice particles in cirrus clouds, Geophys. Res. Lett., 33, L08806, doi:10.1029/2006GL025927, 2006.

Kärcher, B., Abbatt, J. P. D., Cox, R. A., Popp, P. J., and Voigt, C.: Trapping of trace gases by growing ice surfaces including surface-saturated adsorption, J. Geophys. Res., 114, D13306, doi:10.1029/2009JD011857, 2009.

Kondo, Y., Toon, O. B., Irie, H., Gamblin, B., Koike, M., Takegawa, N., Tolbert, M. A., Hudson, P. K., Viggiano, A. A., Avallone, L. M., Hallar, A. G., Anderson, B. E., Sachse, G. W., Vay, S. A., Hunton, D. E., Ballenthin, J. O., and Miller, T. M.: Uptake of reactive nitrogen on cirrus cloud particles in the upper troposphere and lowermost stratosphere, Geophys. Res. Lett., 30, 1154, doi:10.1029/2002GL016539, 2003.

Krämer, M., Schiller, C., Voigt, C., Schlager, H., and Popp, P. J.: A climatological view of $\mathrm{HNO}_{3}$ partitioning in cirrus clouds, Q. J. Roy. Meteor. Soc., 134, 905-912, doi:10.1002/qj.253, 2008.

Lawrence, M. G. and Crutzen, P. J.: The impact of cloud particle gravitational settling on soluble trace gas distributions, Tellus, 50B, 263-289, 1998.

Lawrence, M. G., Crutzen, P. J., Rasch, P. J., Eaton, B. E., and Mahowald, N. M.: A model for studies of tropospheric photochemistry: Description, global distributions, and evaluation, J. Geophys. Res., 104, 26245-26277, 1999.

Levine, S. Z. and Schwartz, S. E.: In-cloud and below-cloud scavenging of nitric acid vapor, Atmos. Environ., 16, 1725-1734, 1982.

Li, Z., Friedl, R. R., Moore, S. B., and Sander, S. P.: Interaction of peroxynitric acid with solid $\mathrm{H}_{2} \mathrm{O}$ ice, J. Geophys., Res., 101, 6795-6802, 1996.

Lin, Y. L., Farley, R. D., and Orville, H. D.: Bulk parametrization of the snow field in a cloud model, J. Clim. Appl. Meteorol., 22, 1065-1092, 1983.

Liu, H., Jacob, D. J., Bey, I., and Yantosca, R. M.: Constraints from ${ }^{210} \mathrm{~Pb}$ and ${ }^{7} \mathrm{Be}$ on wet deposition and transport in a global threedimensional chemical tracer model driven by assimilated meteorological fields, J. Geophys. Res., 106, 12109-12128, 2001.

Liu, X., Penner, J. E., Das, B., Bergmann, D., Rodriguez, J. M., Strahan, S., Wang, M., and Feng, Y.: Uncertainties in global aerosol simulations: Assessment using three meteorological data sets, J. Geophys. Res., 112, D11212, doi:10.1029/2006JD008216, 2007.

Lohmann, U. and Roeckner, E.: Design and performance of a new cloud microphysics scheme developed for the ECHAM general circulation model, Clim. Dynam., 12, 556-572, 1996.

Long, Y., Chaumerliac, N., Deguillaume, L., Leriche, M., and Champeau, F.: Effect of mixed-phase cloud on the chemical budget of trace gases: A modeling approach, Atmos. Res., 97, 540554, 2010.

Mari, C., Jacob, D. J., and Bechtold, P.: Transport and scavenging of soluble gases in a deep convective cloud, J. Geophys. Res., 105, 22255-22267, 2000.

Marshall, K. S. and Palmer, W. M.: The distribution of raindrops with size, J. Meteorol., 5, 165-166, 1948.

Martin, R. V., Sauvage, B., Folkins, I., Sioris, C. E., Boone, C., Bernath, P., and Ziemke, J. R.: Space-based constraints on the production of nitric oxide by lightning, J. Geophys. Res., 112, D09309, doi:10.1029/2006JD007831, 2007.

Mickley, L. J., Murti, P. P., Jacob, D. J., Logan, J. A., Rind, D., and Koch, D.: Radiative forcing from tropospheric ozone calculated 
with a unified chemistry-climate model, J. Geophys. Res., 104, 30153-30172, 1999.

Neu, J. L., Prather, M. J., and Penner, J. E.: Global atmospheric chemistry: Integrating over fractional cloud cover, J. Geophys, Res., 112, D11306, doi:10.1029/2006JD008007, 2007.

Neu, J. L., Lawler, M. J., Prather, M. J., and Saltzman, E. S.: Oceanic alkyl nitrates as a natural source of tropospheric ozone, Geophys. Res. Lett., 35, L13814, doi:10.1029/2008GL034189, 2008.

Olivier, J. G. J., Bouwman, A. F., van der Maas, C. W. M., Berdowski, J. J. M., Veldt, C., Bloos, J. P. J., Visschedijk, A. J. H., Zandveld, P. Y. J., and Haverlag, J. L.: Description of EDGAR version 2.0: A set of global emission inventories of greenhouse gases and ozone-depleting substances for all anthropogenic and most natural sources on a per country basis and on $1^{\circ} \times 1^{\circ}$ grid, RIVM/TNO Rep. 771060-002, 140 pp., 1986.

Popp, P. J., Gao, R. S., Marcy, T. P., Fahey, D. W., Hudson, P. K., Thompson, T. L., Kärcher, B., Ridley, B. A., Weinheimer, A. J., Knapp, D. J., Montzka, D. D., Baumgardner, D., Garrett, T. J., Weinstock, E. M., Smith, J. B., Sayres, D. S., Pittman, J. V., Dhaniyala, S., Bui, T. P., and Mahoney, M. J.: Nitric Acid Uptake on Subtropical Cirrus Cloud Particles, J. Geophys. Res., 109, D06302, doi:10.1029/2003JD004255, 2004.

Rasch, P. J., Feichter, J., Law, K., Mahowald, N., Penner, J., Benkovitz, C., Genthon, C., Giannakopoulous, C., Kashibatla, P., Koch, D., Levy, H., Maki, T., Prather, M., Roberts, D. L., Roelofs, G.-J., Stevenson, D., Stockwell, Z., Taguchi, S., Kritz, M., Chipperfield, M., Baldocchi, D., McMurry, P., Barrie, L., Balkanski, Y., Chatfield, R., Kjellstrom, E., Lawrence, M., Lee, H. N., Lelieveld, J., Noone, K. J., Seinfeld, J., Stenchikov, G., Schwartz, S., Walcek, C., and Williamson, D.: A comparison of scavenging and deposition processes in global models: results from the WCRP Cambridge Workshop of 1995, Tellus, 52B, 1025-1056, 2000.

Rotstayn, L. D.: A physically based scheme for the treatment of stratiform clouds and precipitation in large-scale models, 1 , Description and evaluation of the microphysical processes, Q. J. Roy. Meteor. Soc., 123, 1227-1282, 1997.

Rotstayn, L. D. and Lohmann, U.: Simulation of the tropospheric sulfur cycle in a global model with a physically based cloud scheme, J. Geophys. Res., 107, 4592, doi:10.1029/2002JD002128, 2002.

Salzmann, M., Lawrence, M. G., Phillips, V. T. J., and Donner, L. J.: Model sensitivity studies regarding the role of the retention coefficient for the scavenging and redistribution of highly soluble trace gases by deep convective cloud systems, Atmos. Chem. Phys., 7, 2027-2045, doi:10.5194/acp-7-2027-2007, 2007.

Scheuer, E., Dibb, J. E., Twohy, C., Rogers, D. C., Heymsfield, A. J., and Bansemer, A.: Evidence of nitric acid uptake in warm cirrus anvil clouds during the NASA TC4 campaign, J. Geophys. Res., 115, D00J03, doi:10.1029/2009JD012716, 2010.

Srivastava, R. C.: Size distribution of raindrops generated by their breakup and coalescence, J. Atmos. Sci., 28, 410-415, 1971.

Staudt, A. C., Jacob, D. J., Ravetta, F., Logan, J. A., Bachiochi, D., Krishnamurti, T. N., Sandholm, S., Ridley, B., Singh, H. B., and Talbot, B.: Sources and chemistry of nitrogen oxides over the tropical Pacific, J. Geophys. Res., 108, 8239, doi:10.1029/2002JD002139, 2003.
Stuart, A. L. and Jacobson, M. Z.: A timescale investigation of volatile chemical retention during hydrometeor freezing: Nonrime freezing and dry growth riming without spreading, J. Geophys. Res., 108, 4178, doi:10.1029/2001JD001408, 2003.

Stuart, A. L. and Jacobson, M. Z.: Chemical retention during dry growth riming, J. Geophys. Res., 109, D07305, doi:10.1029/2003JD004197, 2004.

Tabazadeh, A., Toon, O. B., and Jensen, E. J.: A surface chemistry model for nonreactive trace gas adsorption on ice: Implications for nitric acid scavenging by cirrus, Geophys. Res. Lett., 26, 2211-2214, doi:10.1029/1999GL900501, 1999.

Tost, H., Jöckel, P., Kerkweg, A., Sander, R., and Lelieveld, J.: Technical note: A new comprehensive SCAVenging submodel for global atmospheric chemistry modelling, Atmos. Chem. Phys., 6, 565-574, doi:10.5194/acp-6-565-2006, 2006.

Tost, H., Jöckel, P., Kerkweg, A., Pozzer, A., Sander, R., and Lelieveld, J.: Global cloud and precipitation chemistry and wet deposition: tropospheric model simulations with ECHAM5/MESSy1, Atmos. Chem. Phys., 7, 2733-2757, doi:10.5194/acp-7-2733-2007, 2007.

Ullerstam, M. and Abbatt, J. P. D.: Burial of gas-phase $\mathrm{HNO}_{3}$ by growing ice surfaces under tropospheric conditions, Phys. Chem. Chem. Phys., 7, 3596-3600, 2005.

Ullerstam, M., Thornberry, T., and Abbatt, J. P. D.: Uptake of gas phase nitric acid to ice at low partial pressures: evidence for unsaturated surface coverage, Faraday Discuss., 130, 211-226, doi:10.1039/b417418f, 2005.

Voigt, C., Schlager, H., Ziereis, H., Kärcher, B., Luo, B. P., Schiller, C., Krämer, M., Popp, P. J., Irie, H., and Kondo, Y.: Nitric acid uptake in cirrus clouds, Geophys. Res. Lett., 33, L05803, doi:10.1029/2005GL025159, 2006

Voigt, C., Kärcher, B., Schlager, H., Schiller, C., Krämer, M., de Reus, M., Vössing, H., Borrmann, S., and Mitev, V.: In-situ observations and modeling of small nitric acid-containing ice crystals, Atmos. Chem. Phys., 7, 3373-3383, doi:10.5194/acp7-3373-2007, 2007.

Voigt, C., Schlager, H., Roiger, A., Stenke, A., de Reus, M., Borrmann, S., Jensen, E., Schiller, C., Konopka, P., and Sitnikov, N.: Detection of reactive nitrogen containing particles in the tropopause region - evidence for a tropical nitric acid trihydrate (NAT) belt, Atmos. Chem. Phys., 8, 7421-7430, doi:10.5194/acp-8-7421-2008, 2008.

von Kuhlmann, R. and Lawrence, M. G.: The impact of ice uptake of nitric acid on atmospheric chemistry, Atmos. Chem. Phys., 6, 225-235, doi:10.5194/acp-6-225-2006, 2006.

von Kuhlman, R., Lawrence, M. G., and Crutzen, P. J.: A model for studies of tropospheric ozone and nonmethane hydrocarbons: Model description and ozone results, J. Geophys. Res., 108, 4294, doi:10.1029/2002JD002893, 2003.

Wild, O., Sundet, J. K., Prather, M. J., Isaksen, I. S. A., Akimoto, H., Browell, E. V., and Oltmans, S. J.: Chemical transport model ozone simulations for spring 2001 over the western $\mathrm{Pa}$ cific: Comparisons with TRACE-P lidar, ozonesondes, and Total Ozone Mapping Spectrometer columns, J. Geophys. Res., 108, 8826, doi:10.1029/2002JD003283, 2003.

Zondlo, M. A., Barone, S. B., and Tolbert, M. A.: Uptake of $\mathrm{HNO}_{3}$ on ice under upper tropospheric conditions, Geophys. Res. Lett., 24, 1391-1394, 1997. 